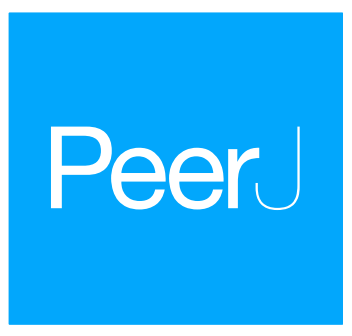

\title{
Virus discovery in all three major lineages of terrestrial arthropods highlights the diversity of single-stranded DNA viruses associated with invertebrates
}

\author{
Karyna Rosario ${ }^{1}$, Kaitlin A. Mettel ${ }^{1}$, Bayleigh E. Benner ${ }^{1}$, \\ Ryan Johnson $^{1}$, Catherine Scott ${ }^{2}$, Sohath Z. Yusseff-Vanegas ${ }^{3}$, \\ Christopher C.M. Baker ${ }^{4,5}$, Deby L. Cassill ${ }^{6}$, Caroline Storer ${ }^{7}$, \\ Arvind Varsani ${ }^{8,9}$ and Mya Breitbart ${ }^{1}$ \\ ${ }^{1}$ College of Marine Science, University of South Florida, Saint Petersburg, FL, USA \\ ${ }^{2}$ Department of Biological Sciences, University of Toronto, Scarborough, Scarborough, \\ ON, Canada \\ ${ }^{3}$ Department of Biology, University of Vermont, Burlington, VT, USA \\ ${ }^{4}$ Department of Ecology and Evolutionary Biology, Princeton University, Princeton, NJ, USA \\ ${ }^{5}$ Department of Organismic and Evolutionary Biology, Harvard University, Cambridge, MA, USA \\ ${ }^{6}$ Department of Biological Sciences, University of South Florida Saint Petersburg, \\ Saint Petersburg, FL, USA \\ ${ }^{7}$ School of Forest Resources and Conservation, University of Florida, Gainesville, FL, USA \\ ${ }^{8}$ The Biodesign Center for Fundamental and Applied Microbiomics, School of Life Sciences, \\ Center for Evolution and Medicine, Arizona State University, Tempe, AZ, USA \\ ${ }^{9}$ Structural Biology Research Unit, Department of Clinical Laboratory Sciences, \\ University of Cape Town, Cape Town, South Africa
}

Submitted 3 August 2018 Accepted 16 September 2018 Published 11 October 2018

Corresponding author

Karyna Rosario,

krosari2@mail.usf.edu

Academic editor

Ana Grande-Pérez

Additional Information and Declarations can be found on page 27

DOI 10.7717/peerj.5761

(c) Copyright

2018 Rosario et al.

Distributed under

Creative Commons CC-BY 4.0

OPEN ACCESS

\section{ABSTRACT}

Viruses encoding a replication-associated protein (Rep) within a covalently closed, single-stranded (ss)DNA genome are among the smallest viruses known to infect eukaryotic organisms, including economically valuable agricultural crops and livestock. Although circular Rep-encoding ssDNA (CRESS DNA) viruses are a widespread group for which our knowledge is rapidly expanding, biased sampling toward vertebrates and land plants has limited our understanding of their diversity and evolution. Here, we screened terrestrial arthropods for CRESS DNA viruses and report the identification of 44 viral genomes and replicons associated with specimens representing all three major terrestrial arthropod lineages, namely Euchelicerata (spiders), Hexapoda (insects), and Myriapoda (millipedes). We identified virus genomes belonging to three established CRESS DNA viral families (Circoviridae, Genomoviridae, and Smacoviridae); however, over half of the arthropod-associated viral genomes are only distantly related to currently classified CRESS DNA viral sequences. Although members of viral and satellite families known to infect plants (Geminiviridae, Nanoviridae, Alphasatellitidae) were not identified in this study, these plant-infecting CRESS DNA viruses and replicons are transmitted by hemipterans. Therefore, members from six out of the seven established CRESS DNA viral families circulate among arthropods. Furthermore, a phylogenetic analysis of Reps, including endogenous viral sequences, reported to date from a wide array of organisms revealed that most of the known CRESS DNA viral diversity circulates among invertebrates. Our results highlight the vast and 
unexplored diversity of CRESS DNA viruses among invertebrates and parallel findings from RNA viral discovery efforts in undersampled taxa.

Subjects Biodiversity, Entomology, Genomics, Microbiology, Virology

Keywords Invertebrate, Arthropod, CRESS DNA, ssDNA, Replication-associated protein (Rep),

Spider, Insect, Discovery, Virus, Endogenous

\section{INTRODUCTION}

Virus discovery remains an open-ended endeavor with estimates of more than $99 \%$ of viruses within organisms remaining to be sampled (Geoghegan \& Holmes, 2017). Eukaryotic viruses infecting vertebrates, mainly mammals, and land plants are overrepresented in public databases relative to those infecting invertebrates and unicellular organisms (Mahmoudabadi \& Phillips, 2018). Therefore, biased sampling has heavily skewed our view of viral diversity and evolution and there is a need to explore "non-traditional" organisms. Efforts investigating single-stranded (ss)RNA viruses in undersampled taxa have identified arthropods, the most diverse and successful group of animals on Earth (Stork, 2018), as a rich and untapped reservoir of novel viruses (Li et al., 2015; Shi et al., 2016a). Moreover, discovery of divergent viruses in invertebrates has prompted reevaluation of RNA virus evolution concepts and taxonomic frameworks (Dolja \& Koonin, 2018; Shi et al., 2016b, Shi, Zhang \& Holmes, 2018b). Notably, these studies have identified arthropods as the ultimate ancestral source of some vertebrate- and plant-infecting RNA viruses (Shi et al., 2016a). Since arthropods may be central to the evolutionary history of other viral groups, here we survey terrestrial arthropods for the presence of ssDNA viruses with circular genomes, which follow positive-sense ssRNA viruses as the second most abundant group of viruses infecting eukaryotes (Mahmoudabadi \& Phillips, 2018; NCBI, 2018). This study focuses on a subset of eukaryotic ssDNA viruses with covalently-closed circular genomes that encode a replication-associated protein (Rep).

Prior to 2009, eukaryotic circular Rep-encoding ssDNA (CRESS DNA) viruses were thought to be restricted to plants (Geminiviridae and Nanoviridae families) and vertebrates (family Circoviridae), specifically pigs and birds (Lefkowitz et al., 2018). Since then, metagenomic studies have revealed the cosmopolitan and diverse nature of eukaryotic CRESS DNA viruses. CRESS DNA viruses have now been reported from a wide array of organisms, ranging from primates (Kapusinszky et al., 2017; $\mathrm{Ng}$ et al., 2015) to unicellular algae (Yoon et al., 2011), and ecosystems spanning aquatic (Dayaram et al., 2015a; Hewson et al., 2013a; Labonté \& Suttle, 2013; Lopez-Bueno et al., 2009), terrestrial (Kim et al., 2008; Reavy et al., 2015), airborne (Whon et al., 2012) and man-made environments (Kraberger et al., 2015; Rosario, Duffy \& Breitbart, 2009; Rosario et al., 2018). The increased detection and expanded diversity of CRESS DNA viruses has resulted in the establishment of four new taxonomic groups by the International Committee for the Taxonomy of Viruses, including three new families (Genomoviridae, Smacoviridae, Bacilladnaviridae) and the Cyclovirus genus within the family Circoviridae, to accommodate these diverse 
viruses (Kazlauskas et al., 2017; Krupovic et al., 2016; Rosario et al., 2017; Varsani \& Krupovic, 2018). Moreover, many CRESS DNA viruses, which are predicted to represent novel families, remain unclassified. In addition, the investigation of endogenous viral sequences has revealed the ancient origin of CRESS DNA viruses by providing evidence indicating that some of these viruses have been infecting diverse animal and plant hosts for millions of years (Belyi, Levine \& Skalka, 2010; Dennis et al., in press; Lefeuvre et al., 2011). Although integration into host chromosomes may be incidental (Krupovic \& Forterre, 2015), CRESS DNA endogenous viral elements may influence host evolution and biology by contributing to their genetic composition and, perhaps, providing new functional capabilities (Belyi, Levine \& Skalka, 2010; Feschotte \& Gilbert, 2012). Therefore, eukaryotic CRESS DNA viruses are a highly diverse group of viruses that have implications well beyond their recognized agricultural and medical relevance.

All eukaryotic CRESS DNA viruses are minimalists; their small circular genomes $(<6 \mathrm{~kb})$ encode $<8$ proteins, including a distinctive homologous Rep (Kazlauskas et al., 2017; Rosario, Duffy \& Breitbart, 2012). Another salient feature of most CRESS DNA viral genomes is a conserved putative origin of replication (ori) marked by a nonanucleotide motif at the apex of a predicted stem-loop structure where rolling circle replication (RCR) is initiated (Rosario, Duffy \& Breitbart, 2012). The presence of a capsid-encoding ORF (open reading frame (ORF)) distinguishes CRESS DNA viruses from CRESS DNA satellite molecules or replicons, such as those classified within the family Alphasatellitidae (Briddon et al., 2018). Although these circular molecules do not encode a capsid, a hallmark defining feature of viruses, these replicons have been considered part of the "extended viral world" as these molecules represent successful genetic parasites (Koonin \& Dolja, 2014).

It has been hypothesized that CRESS DNA viruses may have evolved from interactions between capsid protein genes from RNA viruses and bacterial plasmids on several independent occasions (Koonin, Dolja \& Krupovic, 2015; Krupovic, 2013). The polyphyletic nature of CRESS DNA viruses, complemented by their high substitution rates (Duffy \& Holmes, 2009; Duffy, Shackelton \& Holmes, 2008; Firth et al., 2009) and predisposition to recombination (Lefeuvre et al., 2009; Martin et al., 2011), even within the rep gene (Kazlauskas, Varsani \& Krupovic, 2018; Krupovic et al., 2015), have resulted in the emergence of a highly diverse viral group. This diversity is also reflected by different genome architectures that, similar to RNA viruses (Li et al., 2015; Shi et al., 2016a), suggest plasticity in CRESS DNA virus genomes. CRESS DNA viruses, including viruses classified within the same genus (e.g., Begomovirus), can have monopartite or multipartite genomes. Notably, multipartite genomes have only been observed in plant-infecting CRESS DNA viruses. Based on the arrangement of major ORFs relative to the putative ori, CRESS DNA genomes display eight genome organizations, including those that only encode a Rep and might represent segments of multipartite genomes or satellite molecules (Rosario, Duffy \& Breitbart, 2012). However, there does not seem to be a correlation between these genome organizations and phylogenetic relationships amongst various CRESS DNA viruses (Quaiser et al., 2016; Rosario et al., 2015a). The evolutionary history of some CRESS DNA viruses is further 
obscured by rampant gene fragment exchanges that have led to chimeric Rep sequences that hinder taxonomic classification (Kazlauskas, Varsani \& Krupovic, 2018). Despite these limitations, the Rep remains the only tractable phylogenetic marker that can be used to investigate evolutionary relationships among the highly diverse and polyphyletic CRESS DNA viruses.

Most viral discovery studies focus on vertebrate hosts, primarily mammals, which limits our perspective of viral diversity and evolution. The work presented here expands on studies investigating CRESS DNA viruses in invertebrates, which have traditionally been undersampled (Bettarel et al., 2018; Bistolas et al., 2017; Dayaram et al., 2013; Hewson et al., 2013b; Kraberger et al., 2018; Rosario et al., 2012, 2015a; Wang et al., 2018). We report 44 CRESS DNA genomes recovered from arthropods representing all three major terrestrial arthropod lineages (Giribet \& Edgecombe, 2012). By performing a phylogenetic analysis of Reps from CRESS DNA genomes reported from a wide array of organisms and those identified as endogenous viral elements, we demonstrate that most of the previously described CRESS DNA viral phylogenetic diversity circulates among invertebrates. In addition, database searches using newly detected Reps led to the detection of an unreported endogenous cyclovirus-like element within a genome scaffold from a rodent-infecting nematode. Although cycloviruses have been mainly detected in feces from various mammals and homogenized tissues from insects (Rosario et al., 2017), endogenous cyclovirus elements indicate that these viruses are able to infect both arthropod (mites) (Dennis et al., 2018; Liu et al., 2011) and non-arthropod parasitic invertebrates.

\section{MATERIALS AND METHODS Sample collection and processing}

A variety of opportunistically sampled arthropods were screened for CRESS DNA viral sequences (Table 1). Samples included members from all three major groups of terrestrial arthropods including Hexapoda (Class Insecta; Orders: Hymenoptera, Coleoptera, Odonata, Dermaptera, Diptera, Orthoptera, Lepidoptera, Ephemeroptera, Blattodea), Euchelicerata (Class Arachnida; Order: Araneae), and Myriapoda (Classes: Diplopoda and Chilopoda). All specimens were identified to the most specific taxonomic rank possible through identification by experts or using DNA barcoding (see below) when taxonomic identifications were not available. Samples were processed following methods used to detect CRESS DNA viruses in marine invertebrates (Rosario et al., 2015a) and insects (Dayaram et al., 2013; Rosario et al., 2012). Briefly, specimens were serially rinsed three times using sterile suspension medium (SM) buffer [0.1M NaCl, $50 \mathrm{mM}$ Tris- $\mathrm{HCl}(\mathrm{pH}$ 7.5), $10 \mathrm{mM} \mathrm{MgSO}_{4}$ ] to remove debris. A small piece of tissue was dissected from representative specimens and stored at $-20{ }^{\circ} \mathrm{C}$ for DNA barcoding. Each specimen or pooled sample composed of up to 10 specimens from the same species was homogenized in SM buffer through bead-beating using $1.0 \mathrm{~mm}$ sterile glass beads in a bead beater (Biospec Products, Bartlesville, OK, USA) for 60-90 s and homogenates were centrifuged at $6,000 \times g$ for $6 \mathrm{~min}$. Viral particles

were then partially purified from supernatants by filtering through a $0.45 \mu \mathrm{m}$ Sterivex filter 
Table 1 Sample information and identified CRESS DNA genomes.

\begin{tabular}{|c|c|c|c|c|}
\hline Year & Location $^{1}$ & Species name (common name) $)^{2}$ & Samples $^{3}$ & Identified genomes \\
\hline 2011 & Kenya & Crematogaster nigriceps (Arboreal ant) & Pool (2) & Arboreal ant associated circular virus 1 \\
\hline 2011 & Kenya & Tetraponera penzigi (Arboreal ant) & Pool (2) & Arboreal ant associated circular virus 1 \\
\hline 2011 & Kenya & Crematogaster mimosae (Arboreal ant) & Pool & Arboreal ant associated circular virus 1 \\
\hline 2013 & FL USA & Solenopsis invicta (Fire ant) & Pool & Fire ant associated circular virus 1 \\
\hline 2013 & FL USA & Xylosandrus amputates (Bark beetle) & Pool & Bark beetle associated circular virus 1 \\
\hline 2014 & Puerto Rico & Dineuteus sp. (Water beetle)* & Single (4) & Water beetle associated circular virus 1 \\
\hline 2013 & Store & Gryllus assimilis (Field cricket) & Pool & Cricket associated circular virus 1 \\
\hline 2011 & FL USA & Romulea microptera (Lubber grasshopper) & Single & Grasshopper associated circular virus 1 \\
\hline \multirow[t]{3}{*}{2013} & Nevis & Lucilia rica (Blow fly)* & Pool & Fly associated circular virus 1 \\
\hline & & & & Fly associated circular virus 3 \\
\hline & & & & Fly associated circular virus 5 \\
\hline 2013 & St. Barts & Fannia sp. (Dung fly)* & Pool & Fly associated circular virus 2 \\
\hline 2013 & Dom. Republic & Lucilia retroversa (Blow fly) & Pool & Fly associated circular virus 4 \\
\hline 2013 & Guadeloupe & Lucilia rica (Blow fly)* & Pool & Fly associated circular virus 6 \\
\hline 2013 & St. Barts & Lucilia rica. (Blow fly)* & Pool & Fly associated circular virus 7 \\
\hline 2015 & NH USA & Oxidus sp. (Greenhouse millipede)* & Single & Millipede associated circular virus 1 \\
\hline 2017 & Victoria BC & Parasteatoda tepidariorum (Common house spider) & Single & Common house spider circular molecule 1 \\
\hline 2017 & Victoria BC & Cybaeus signifer & Single & Cybaeus spider associated circular virus 1 \\
\hline 2017 & Victoria BC & Cybaeus signifer & Single & Cybaeus spider associated circular virus 2 \\
\hline 2017 & Victoria BC & Cybaeus signifer & Single & Cybaeus spider associated circular molecule 1 \\
\hline 2017 & Victoria BC & Steatoda grossa (False black widow spider) & Single & False black widow spider associated circular virus 1 \\
\hline 2017 & Victoria BC & Eratigena duellica (Giant house spider) & Single & Giant house spider associated circular virus 1 \\
\hline 2017 & Victoria BC & Eratigena duellica (Giant house spider) & Single & Giant house spider associated circular virus 2 \\
\hline 2017 & Victoria BC & Eratigena duellica (Giant house spider) & Single & Giant house spider associated circular virus 3 \\
\hline 2017 & Victoria BC & Eratigena duellica (Giant house spider) & Single (2) & Giant house spider associated circular virus 4 \\
\hline 2014 & Puerto Rico & Nephila sp. (Golden silk orbweaver)* & Single & Golden silk orbweaver associated circular virus 1 \\
\hline 2017 & FL USA & Leucauge argyra (Longjawed orbweaver)* & Single & Longjawed orbweaver circular virus 1 \\
\hline 2014 & Puerto Rico & Leucauge argyra (Longjawed orbweaver)* & Single & Longjawed orbweaver circular virus 2 \\
\hline 2017 & Victoria BC & Pimoa altioculata (Pimoid spider)* & Single & Pimoid spider associated circular virus 1 \\
\hline \multirow[t]{2}{*}{2017} & Victoria BC & Pimoa altioculata (Pimoid spider)* & Single & Pimoid spider associated circular virus 2 \\
\hline & & & & Pimoid spider associated circular molecule 1 \\
\hline 2017 & Victoria BC & Neriere litigiosa (Sierra dome spider)* & Single & Sierra dome spider associated circular virus 1 \\
\hline 2017 & Victoria BC & Neriere litigiosa (Sierra dome spider)* & Single & Sierra dome spider associated circular virus 2 \\
\hline 2017 & Victoria BC & Cybaeidae (Soft spider) & Single & Soft spider associated circular virus 1 \\
\hline 2017 & Victoria BC & Cybaeus signifer & Single & Spider associated circular virus 1 \\
\hline 2017 & Victoria BC & Segestria pacifica (Tubeweb spider) & Single & Spider associated circular virus 1 \\
\hline 2017 & Victoria BC & Eratigena atrica (Giant house spider) & Single & Spider associated circular virus 1 \\
\hline 2017 & Victoria BC & Parasteatoda tepidariorum (Common house spider) & Single & Spider associated circular virus 2 \\
\hline 2017 & Victoria BC & Segestria pacifica (Tubeweb spider)* & Single & Spider associated circular virus 3 \\
\hline 2014 & FL USA & Gasteracantha cancriformis (Spinybacked orbweaver)* & Single & Spinybacked orbweaver circular virus 1 \\
\hline 2017 & FL USA & Gasteracantha cancriformis (Spinybacked orbweaver)* & Single & Spinybacked orbweaver circular virus 1 \\
\hline
\end{tabular}


Table 1 (continued).

\begin{tabular}{lllll} 
Year & Location $^{1}$ & Species name (common name) & Samples $^{3}$ & Identified genomes $^{2}$ \\
\hline 2017 & FL USA & Gasteracantha cancriformis (Spinybacked orbweaver) & Single & Spinybacked orbweaver circular virus 2 \\
2017 & FL USA & Cyrtophora sp. (Tentweb spider) & Single & Tentweb spider associated circular virus 1 \\
2017 & Victoria BC & Segestria pacifica (Tubeweb spider) & Single & Tubeweb spider associated circular virus 1 \\
2017 & Victoria BC & Dysdera crocata (Woodlouse hunter spider) & Single & Woodlouse hunter spider associated circular virus 1 \\
2015 & Kenya & Odontotermes sp. (Fungus-farming termite) & Pool & Termite associated circular virus 1 \\
& & & & Termite associated circular virus 3 \\
& & & Termite associated circular virus 4 \\
2015 & Kenya & Odontotermes sp. (Fungus-farming termite) & Pool (2) & Termite associated circular virus 2 \\
\hline
\end{tabular}

Notes:

Location abbreviations: FL, Florida; NH, New Hampshire; St. Barts, Saint Barthelemy; Dom. Republic, Dominican Republic; BC, British Columbia; Store, Carolina Biological Supply.

${ }^{2}$ Many specimens were taxonomically identified by sample providers. However, some specimens were identified through DNA barcoding and are indicated with an asterisk (*).

Samples processed as individuals (Single) or pools (Pool) composed of up to 10 individuals from the same species are distinguished. Some CRESS DNA genomes were recovered from multiple individuals or pools (the number of samples that independently resulted in the identification of a given genome is specified within parenthesis). Although some genomes represent the same viral species, genomes sharing less than $100 \%$ genome-wide pairwise identity that were recovered from independent samples were submitted to GenBank and assigned individual accession numbers (see Table 3).

(Millipore, Burlington, MA, USA) and nucleic acids were extracted from $200 \mu \mathrm{l}$ of filtrate using the QIAamp MinElute Virus Spin Kit (Qiagen, Hilden, Germany).

DNA barcoding was performed to identify any arthropods positive for CRESS DNA viruses that were not taxonomically identified by experts. For this purpose, DNA was extracted from tissue samples using the Quick-DNA Tissue/Insect Kit (Zymo Research, Irvine, CA, USA) following the manufacturer's instructions. The mitochondrial cytochrome oxidase I (COI) gene was then amplified through polymerase chain reaction (PCR) using the universal COI primers LCO1490 (5'GGTCAACAAATCATAAAGATA TTGG3') and HCO2198 (5'TAAACTTCAGGGTGACCAAAAAATCA3') (Folmer et al., 1994). A total of $50 \mu \mathrm{l}$ PCR reactions contained the following: $1.5 \mathrm{mM} \mathrm{MgCl}$, $1 \times$ Apex $\mathrm{NH}_{4}$ Buffer, $0.5 \mu \mathrm{M}$ primer LCO1490, $0.5 \mu \mathrm{M}$ primer HCO2198, 5\% DMSO, $1 \mu \mathrm{g} / \mu \mathrm{l}$ BSA, 1 U Apex Red Taq DNA Polymerase (Genesee Scientific, San Diego, CA, USA), and $3 \mu \mathrm{l}$ of template DNA. Thermocycling conditions consisted of an initial denaturation at $95^{\circ} \mathrm{C}$ for $2 \mathrm{~min}$, followed by 35 cycles of $94^{\circ} \mathrm{C}$ for $1 \mathrm{~min}, 48^{\circ} \mathrm{C}$ for $1 \mathrm{~min}$ incrementally decreasing the temperature by $0.1{ }^{\circ} \mathrm{C}$ each cycle, and $72{ }^{\circ} \mathrm{C}$ for $1 \mathrm{~min}$, with a final extension at $72{ }^{\circ} \mathrm{C}$ for $7 \mathrm{~min}$. Mitochondrial COI gene PCR products were commercially sequenced using LCO1490 and HCO2198 primers. Sequences were compared against GenBank through BLASTn searches. Sequences sharing $>95 \%$ identity with sequences in the database were classified to species, whereas sequences with nucleotide identities below this threshold were classified at the genus level.

\section{Detection of CRESS DNA viral genomes and genome completion}

Small circular templates, such as CRESS DNA genomes, were enriched by amplifying DNA extracts through rolling circle amplification (RCA) using the Illustra TempliPhi Amplification Kit (GE Healthcare, Chicago, IL, USA) (Haible, Kober \& Jeske, 2006; Kim \& Bae, 2011). RCA products were digested using a suite of six-cutter FastDigest restriction enzymes (Thermo Fisher Scientific, Waltham, MA, USA), including BamHI, 
EcoRV, PdmI, HindIII, KpnI, PstI, XhoI, SmaI, BglII, EcoRI, XbaI, and NcoI. Three microliters of RCA product from each sample were digested with each enzyme in separate reactions following the manufacturer's instructions to obtain complete, unit-length genomes. Products of the restriction digests were resolved on an agarose gel and fragments ranging in size from 1 to $4 \mathrm{~kb}$ were excised and purified using the Zymoclean Gel DNA Recovery Kit (Zymo Research, Irvine, CA, USA) for cloning. Since CRESS DNA viruses have been identified as contaminants in commercial spin columns used for nucleic acid extractions (Krupovic et al., 2015), negative controls containing SM Buffer alone were processed alongside samples from DNA extractions through restriction enzyme digests and, whenever applicable, PCR (see below).

In most cases, products resulting from blunt-cutting enzyme digestions were cloned into the pJET1.2 vector using the CloneJET PCR Cloning kit (Thermo Fisher Scientific, Waltham, MA, USA), whereas products resulting from enzymes producing sticky ends were cloned using pGEM-3Zf(+) vectors (Promega, Madison, WI, USA) pre-digested with the appropriate enzyme. However, if there were difficulties cloning into pre-digested pGEM-3Zf(+) vectors, sticky-end digestion products were cloned into the pJET1.2 vector following the manufacturer's sticky-end cloning protocol. Cloned digest products were then Sanger sequenced using vector primers. If these preliminary sequences showed significant similarities to CRESS DNA viral sequences based on BLASTn or BLASTx searches $(e$-value $<0.001)$, complete genome sequences were obtained through primer walking of cloned unit-length genomes or through inverse PCR using back-to-back primers designed from preliminary sequences. For the latter, PCR products were cloned using the CloneJET PCR Cloning kit and Sanger sequenced using vector primers and primer walking.

\section{CRESS DNA genome sequence analyses}

Circular Rep-encoding ssDNA genome sequences were assembled in Geneious version R7 (Biomatters, Auckland, New Zealand) with default parameters for de novo assemblies. Major, non-overlapping ORFs $>100$ amino acids were identified and annotated using SeqBuilder from the Lasergene software package version 11.2.1 (DNASTAR, Madison, WI, USA) using the standard genetic code. Partial genes or genes that seemed interrupted were screened for potential introns using GENSCAN (Burge \& Karlin, 1997). Genomes that did not contain a putative capsid-encoding ORF, based on BLASTx (Altschul et al., 1990) or remote protein homology searches using HHpred (Söding, Biegert \& Lupas, 2005), were further investigated by looking at intrinsically disorder protein (IDP) profiles of non-Rep encoding ORFs using the neural network based VL3 disorder predictor on DisProt (Sickmeier et al., 2007). If non-Rep encoding ORFs contained a high proportion of disordered residues within the first 100 amino acids, they were considered putative capsid proteins (Rosario et al., 2015a). The potential ori for each genome was identified by locating the canonical nonanucleotide motif "NANTATTAC" observed in most CRESS DNA genomes (Rosario, Duffy \& Breitbart, 2012), or similar sequences (Krupovic et al., 2016; Varsani \& Krupovic, 2018), and evaluating if the identified nonamer was found at the apex of a predicted stem-loop structure using the Mfold web server (Zuker, 2003). Genome-wide and 
Rep amino acid sequence pairwise identities (PIs) were calculated using the Sequence Demarcation Tool version 1.2 (Muhire, Varsani \& Martin, 2014) to evaluate taxonomic relationships among CRESS DNA genomes identified in this study and those found in GenBank.

\section{Phylogenetic analyses}

To evaluate how the novel CRESS DNA sequences identified in this study compared to previously reported CRESS DNA viral genomes, we constructed a phylogenetic tree from Rep amino acid sequences recovered from a wide array of organisms. For this purpose, Rep sequences were downloaded from GenBank in April 2018. These sequences included Reps from members of six established CRESS DNA viral families, including Geminiviridae (nine genera), Nanoviridae (two genera), Circoviridae (two genera), Genomoviridae (nine genera), Bacilladnaviridae (four genera), and Smacoviridae (six genera), as well as satellite molecules from the Alphasatellitidae (11 genera) and other CRESS DNA viral genomes that remain unclassified. To reduce the number of sequences in the analysis while still being able to assess diversity, Rep sequences representing established taxonomic groups were clustered based on a 70\% amino acid identity cut off using CD HIT (Fu et al., 2012). However, if more than 20 sequences remained after clustering for a given group, sequences were clustered using a 50\% identity cut off. All sequences outside of the established CRESS DNA families were grouped by organism (e.g., rodent associated sequences) and sequences within each group were clustered using a $70 \%$ amino acid identity cut off. In addition to sequences representing exogenous viruses and replicons, CRESS DNA-like endogenous viral sequences (CEVs) reported from various organisms were included (Dennis et al., in press, 2018; Liu et al., 2011). Selected CEVs did not contain any early stop codons or frameshifts. The final dataset contained 489 Rep sequences.

An alignment was performed using MUSCLE (Edgar, 2004) as implemented in MEGA7 (Kumar, Stecher \& Tamura, 2016) and manually edited by inspecting and aligning sequences based on the presence of conserved RCR and superfamily 3 (SF3) helicase motifs (Kazlauskas et al., 2017; Rosario et al., 2017; Varsani \& Krupovic, 2017, 2018). The alignment was trimmed close to the RCR motif I and helicase arginine finger motifs and final aligned sequences, including CEVs, were at least 200 amino acids in length (Data S1). The alignment was used to construct an unrooted approximatelymaximum-likelihood (ML) phylogenetic tree using FastTree 2 (Price, Dehal \& Arkin, 2010) with default parameters. The phylogenetic tree was edited using TreeGraph 2 (Stöver \& Müller, 2010) to collapse branches with support below a given threshold of Shimodaira-Hasegawa-like support and FigTree (http://ree.bio.ed.ac.uk/software/figtree/) was used for tree visualization and editing. The same alignment and tree editing strategies were used for all phylogenetic trees presented in this study.

Circular Rep-encoding ssDNA genome sequences representing species from established CRESS DNA viral groups were further investigated for genera and/or species level classification assignment. All species level assignments were based on current species demarcation criteria for CRESS DNA groups (Table 2). However, some genomes with similarities to members of the Genomoviridae and Circoviridae families seemed to 


\begin{tabular}{|c|c|c|c|}
\hline Family & $\begin{array}{l}\text { Genome-wide } \\
\text { pairwise identity }^{1}\end{array}$ & Species demarcation criteria ${ }^{2}$ & Reference \\
\hline \multirow[t]{2}{*}{ Alphasatellitidae } & \multirow[t]{2}{*}{$54 \%$} & Geminialphasatellitinae, $88 \%$ & Briddon et al. (2018) \\
\hline & & Nanoalphasatellitinae, $80 \%$ & Briddon et al. (2018) \\
\hline Bacilladnaviridae & Not reported & $75 \% *$ & Kazlauskas et al. (2017) \\
\hline Circoviridae & $55 \%$ & $80 \%$ & Rosario et al. (2017) \\
\hline \multirow[t]{9}{*}{ Geminiviridae } & \multirow[t]{9}{*}{$54 \%$} & Becurtovirus, $80 \%$ & Varsani et al. (2014b) \\
\hline & & Begomovirus, 91\% & Brown et al. (2015) \\
\hline & & Capulavirus, $78 \%$ & Varsani et al. (2017) \\
\hline & & Curtovirus, $77 \%$ & Varsani et al. (2014a) \\
\hline & & Glabovirus, $80 \%$ & Varsani et al. (2017) \\
\hline & & Mastrevirus, 78\% & Muhire, Varsani \& Martin (2014) \\
\hline & & Eragrovirus, not reported & \\
\hline & & Turncurtovirus, not reported & \\
\hline & & Topocuvirus, not reported & \\
\hline Genomoviridae & $53 \%$ & $78 \%$ & Varsani \& Krupovic (2017) \\
\hline Nanoviridae & Not reported & $75 \%$ & Lefkowitz et al. (2018) \\
\hline Smacoviridae & $55 \%$ & $77 \%$ & Varsani \& Krupovic (2018) \\
\hline
\end{tabular}

fall outside existing genera; thus, further phylogenetic analyses were undertaken to determine the assignment of these CRESS DNA viruses as putative members of these families. Rep sequences representing members from each of the nine Genomoviridae genera and closely related viruses, including geminiviruses, were aligned and a $\mathrm{ML}$ phylogenetic tree was constructed using PhyML (Guindon et al., 2010) with the LG+G+I substitution model. The ML tree was then rooted with viral sequences from members of the Geminiviridae (Varsani \& Krupovic, 2017). For the family Circoviridae, Rep sequences representing members from the Circovirus and Cyclovirus genera as well as closely related sequences and CEVs falling within this family were aligned. A midpoint rooted ML phylogenetic tree was then constructed using PhyML with automatic selection of substitution model through the Smart Model Selection using the Akaike Information Criterion (Lefort, Longueville \& Gascuel, 2017).

\section{RESULTS}

\section{CRESS DNA viruses identified in all three major lineages of terrestrial arthropods}

More than 500 specimens representing a diversity of terrestrial arthropods were analyzed for the presence of CRESS DNA viruses through RCA followed by restriction enzyme digestion and cloning. Our efforts resulted in the detection of 44 unique $(<80 \%$ genome-wide PI) CRESS DNA genomes (Table 3). Consistent with known CRESS DNA genomes, the genomes are small in size $(<3.5 \mathrm{~kb})$ and contain a putative ori marked 


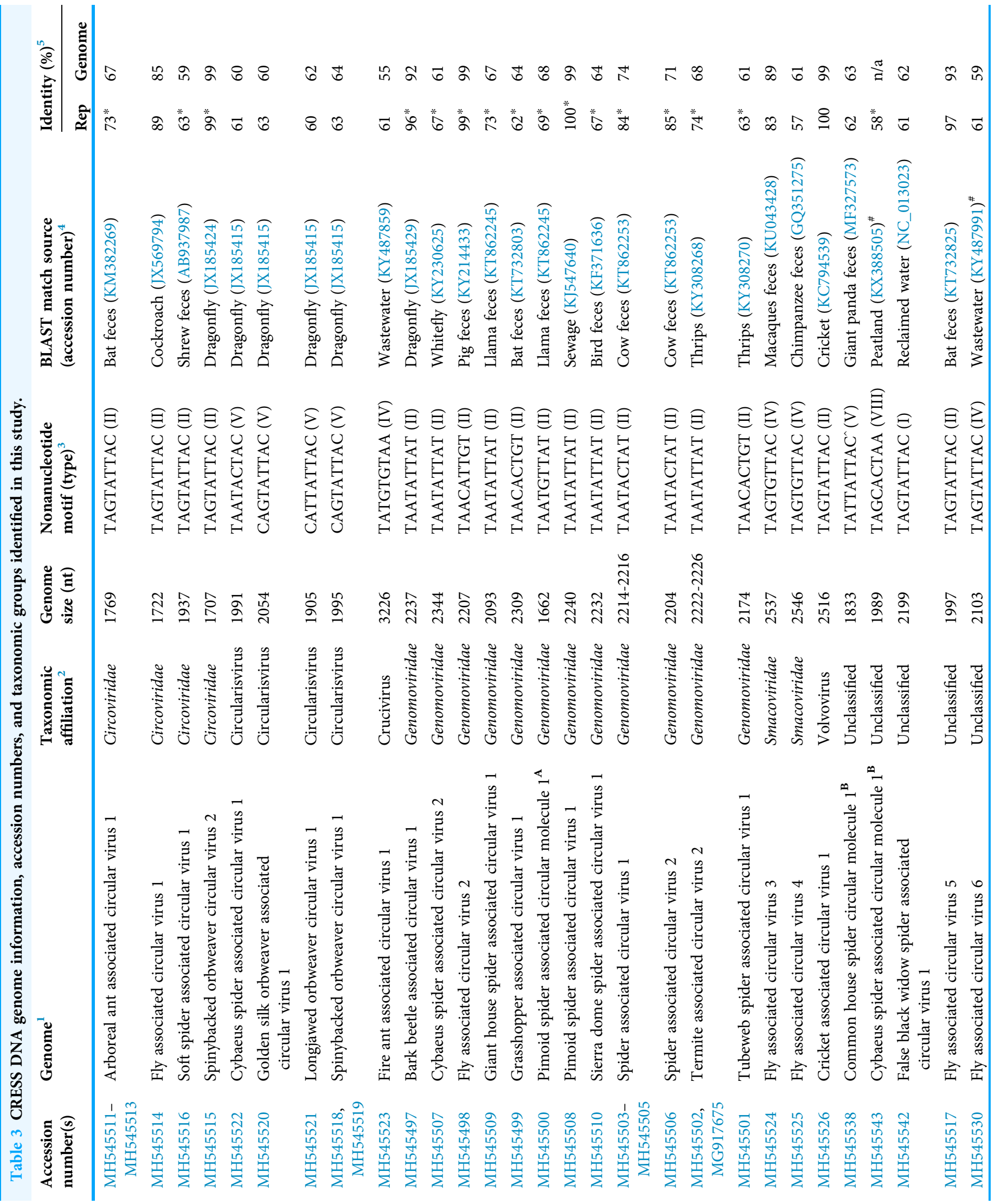




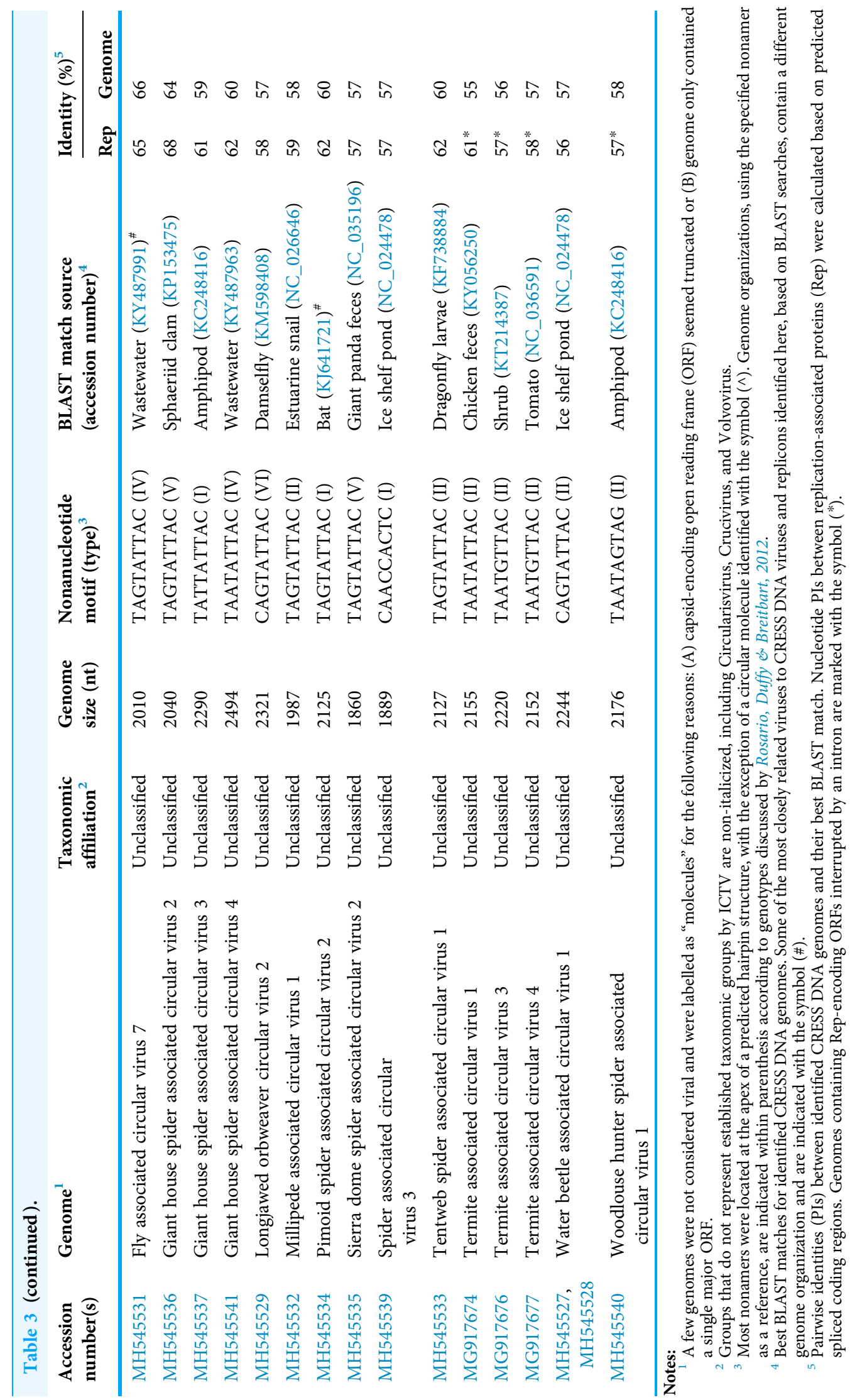


by a conserved nonanucleotide motif at the apex of predicted stem-loop structure. Based on the position of the ori relative to major ORFs, six out of the eight described CRESS DNA genome organizations were detected. (Rosario, Duffy \& Breitbart, 2012). In addition to an identifiable Rep-encoding ORF, most $(n=34)$ of these CRESS DNA genomes encode a putative capsid protein based on similarities to capsid proteins found in public databases. A total of 10 of the detected genomes do not encode an ORF with significant matches to known capsid proteins; however, the non-Rep encoding ORFs in eight of these genomes have similar IDP profiles to those seen in other CRESS DNA viruses, suggesting they encode a putative capsid protein (Data S2) (Rosario et al., 2015a). The three genomes for which a capsid-encoding ORF could not be identified were named as "circular molecules" to distinguish these replicons from bona fide CRESS DNA viral genomes.

Half of the CRESS DNA genomes described here were identified in spiders (Class Arachnida; Order Araneae), despite the fact that $>70 \%$ of the samples processed in this study were insects (Class Insecta; data not shown). The high prevalence of CRESS DNA genomes in spiders is even more striking considering that most spiders were processed individually, as opposed to many of the insect species for which multiple individuals were pooled (Table 1). To our knowledge, these genomes represent the first exogenous CRESS DNA viruses reported from spiders. CRESS DNA viruses were also widely detected in insects with viral genomes retrieved from specimens representing five orders, including ants (Hymenoptera), beetles (Coleoptera), flies (Diptera), grasshoppers and crickets (Orthoptera), and termites (Blattodea). In addition, we detected a genome from a millipede (Class Diplopoda) representing the first CRESS DNA virus associated with a member of the Subphylum Myriapoda. The low number of CRESS DNA viruses identified from members of the Myriapoda may be a consequence of uneven sampling since only seven specimens from this group were processed. Similarly, groups for which no CRESS DNA viruses were identified, including Odonata, Dermaptera, Lepidoptera, Ephemeroptera, and Chilopoda, had low sample numbers $(<10)$ (data not shown).

\section{Terrestrial arthropods harbor diverse novel CRESS DNA viruses}

Over half of the genomes (55\%) identified in this study shared $<70 \%$ genome-wide PI with previously reported sequences (Table 3 ) and could not be assigned to an existing CRESS DNA group. Phylogenetic analysis of Rep amino acid sequences retrieved from a wide array of organisms illustrated the wide phylogenetic distribution of the arthropod CRESS DNA viruses and replicons identified here (Fig. 1). Some of the arthropod-associated CRESS DNA genomes falling outside of established taxonomic groups were most closely related to isolates that have not been assigned to either genera or families. We identified four genomes from spiders that were most closely related to a circularisvirus reported from dragonflies (Rosario et al., 2012). Phylogenetic analysis revealed other circularisvirus-like genomes retrieved from dragonflies (accession KM598396, Dayaram et al., 2015b) and bat feces (accession KT732823, Male et al., 2016) (Fig. 1). All of these circularisvirus-like genomes contained similar genomic features, including unisense organization, similar size $(\sim 1.9-2 \mathrm{~kb})$, and a putative ori on the 


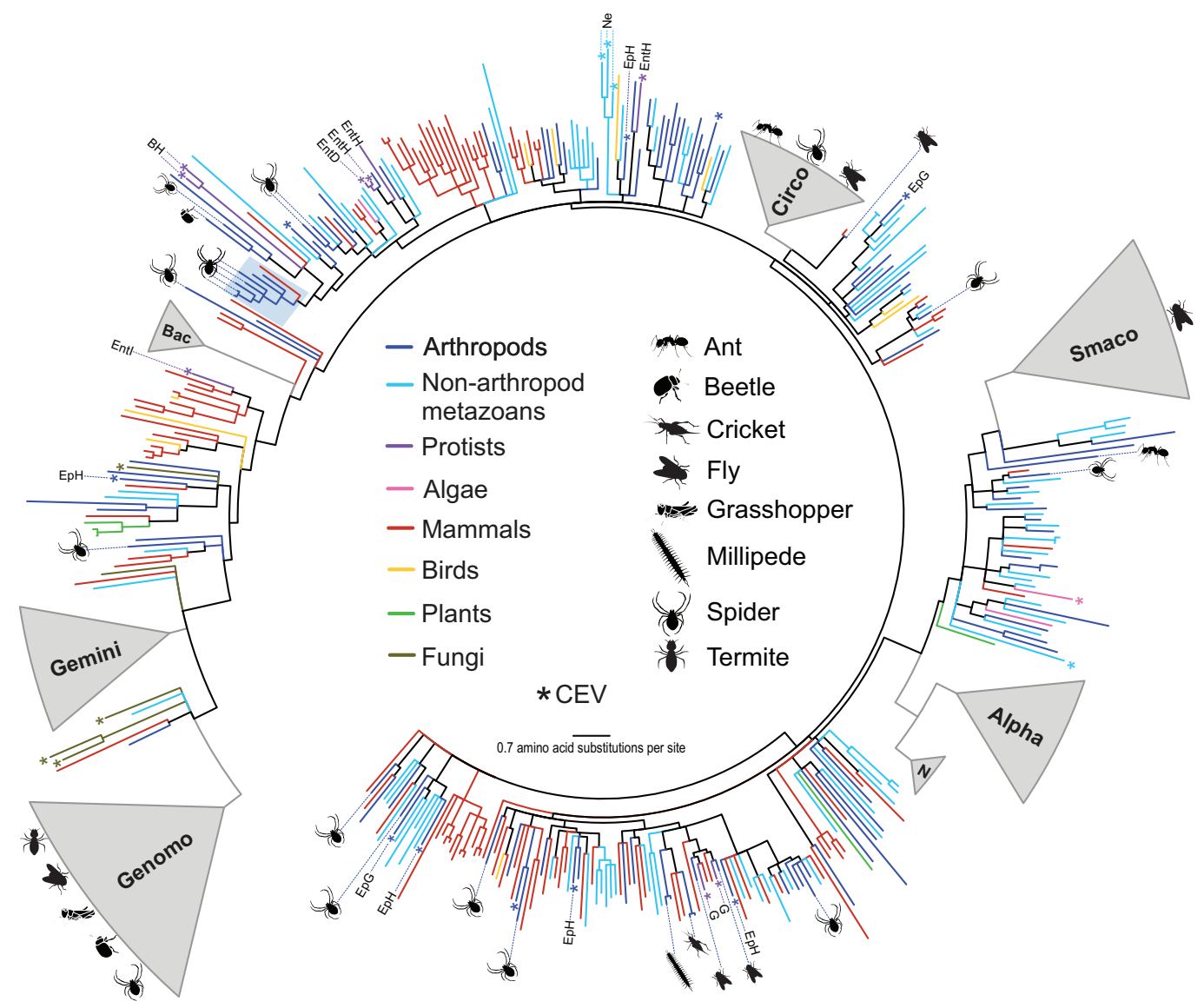

Figure 1 Approximately maximum likelihood phylogenetic tree of replication-associated protein (Rep) amino acid sequences representing CRESS DNA viruses, replicons, and CRESS DNA-like endogenous viral (CEV) elements recovered from various organisms. Branch colors distinguish sequences associated with various types of organisms. Clades containing Rep sequences falling within established CRESS DNA viral groups including the Genomoviridae (Genomo), Geminiviridae (Gemini), Bacilladnaviridae (Bac), Circoviridae (Circo), Smacoviridae (Smaco), Nanoviridae (N) and Alphasatellitidae (Alpha) were merged and are highlighted in gray. The new circularisvirus clade is highlighted with a light blue rectangle. The asterisk symbol indicates branches representing CEVs. Branches representing CEVs identified in Ephydra spp. (dipteran), including E. gracilis (EpG) and E. hians (EpH), and nematodes $(\mathrm{Ne})$ are specified. CEVs identified in protists are also specified, including Entamoeba (Ent), Giardia intestinalis (G) and Blastocystis hominis (BH). Entamoeba species are further distinguished, namely E. invadens (EntI), E. histolytica (EntH), and E. dispar (EntD). Reps identified in this study are highlighted with schematics of terrestrial arthropods showing their source and broad phylogenetic distribution. Branches with $<80 \%$ Shimodaira-Hasegawa (SH)-like support were collapsed. Arthropod silhouettes credit: Shutterstock vector library at https://www.shutterstock.com.

Full-size $\boldsymbol{0}$ DOI: $10.7717 /$ peerj.5761/fig-1

Rep-encoding strand (Table 3). In addition, circularisvirus-like genomes shared $>57 \%$ genome-wide PIs among each other, which is similar to genome-wide PIs reported for established CRESS DNA viral families (Table 2). Conserved circularisvirus genomic characteristics and genome-wide PIs may grant the formation of a new group of CRESS DNA viruses.

Fire ant associated circular virus $1(\mathrm{FaACV}-1)$ has features characteristic of the crucivirus group, members of which have been mainly reported from environmental 
samples (Diemer \& Stedman, 2012; Krupovic et al., 2015; McDaniel et al., 2014; Quaiser et al., 2016; Roux et al., 2013; Steel et al., 2016). Namely, the FaCV-1 genome contains a Rep-encoding ORF most similar to that of CRESS DNA viruses and a putative capsid protein with significant similarities to capsid proteins of ssRNA viruses from the family Tombusviridae. FaCV-1 is most closely related to a crucivirus isolated from wastewater (Table 3). Both FaCV-1 and the wastewater associated crucivirus have two major ORFs arranged in ambisense orientation and share 55\% genome-wide PI, suggesting that these genomes may belong to the same viral family. However, currently there is no classification framework for cruciviruses. In addition, we identified a molecule, cybaeus spider associated circular molecule 1, containing a single ORF most similar to a Rep-encoding ORF from a crucivirus identified from peatland (Quaiser et al., 2016). The findings presented here suggest that cruciviruses circulate in insects and may be associated with both terrestrial and aquatic (Bistolas et al., 2017; Hewson et al., 2013b) arthropods.

Although the aim of this study was to identify CRESS DNA genomes, four novel circular molecules that did not encode a Rep were detected (Data S2). These included two molecules, leaf-footed bug associated circular molecule 1 (LfBACM-1) and Spider associated circular molecule 2 (SACM-2), that only contained a single major ORF encoding a putative capsid. The small genome size $(<1.2 \mathrm{~kb})$ of these molecules is reminiscent of capsid-encoding genomic segments from multipartite CRESS DNA viruses from the family Nanoviridae (Gronenborn, 2004). Indeed, LfBACM-1 is most similar to a genomic segment from a novel multicomponent CRESS DNA virus discovered in the feces of fruit-eating bats (Male et al., 2016). However, the SACM-2 putative capsid protein sequence is most similar to the capsid encoded by a presumably monopartite CRESS DNA virus discovered from a sewage oxidation pond (Kraberger et al., 2015). Surprisingly, the remaining two molecules, longjawed orbweaver circular molecule 1 (LjOrbCM-1) and giant house spider associated circular molecule 1 (GhSACM-1), encoded a protein most similar to the large T antigen (LT) encoded by polyomaviruses. The LjOrbCM-1 genome only contained the LT-encoding ORF, whereas GhSACM-1 encoded an additional major, non-overlapping ORF. However, the non-LT encoding ORF of GhSACM-1 was not predicted to encode a structural protein based on homology searches or IDP profiles. These four non-CRESS DNA molecules will not be discussed further, but these findings are noteworthy since they support studies describing capsid-encoding molecules potentially representing novel multipartite viruses associated with unsuspected organisms (Male et al., 2016) and the presence of episomal polyoma-like replicons in spiders (Buck et al., 2016).

\section{Terrestrial arthropods harbor a diversity of species representing new members of established CRESS DNA viral groups}

The CRESS DNA genomes that could be assigned to previously reported taxa were dominated by members of the family Genomoviridae, which included genomes retrieved from spiders $(n=7)$, flies $(n=2)$, grasshoppers $(n=1)$, and termites $(n=1)$ (Table 3). Phylogenetic analysis based on the Rep indicated that the newly identified viruses belong to three genera (Gemycircularvirus, Gemykibivirus, and Gemykolovirus) 
within the family Genomoviridae (Fig. 2; Fig. S1). The majority of arthropod-associated genomoviruses identified here belong to the genus Gemycircularvirus, which is the genus containing the highest number of species within the family (Varsani \& Krupovic, 2017). Based on the species demarcation criteria of $78 \%$ genome-wide PI (Table 2), two of the seven identified gemycircularviruses represent new isolates from the classified species dragonfly associated gemycircularvirus 1 and sewage derived gemycircularvirus 4 . The remaining five gemycircularviruses represent new species. Spider associated circular viruses (SACVs) 1 and 2 represent a new gemycircularvirus species that was identified in four species of spiders, with SACV-1 and -2 isolates sharing 79-98\% genome-wide PI. In addition to gemycircularviruses, we identified two isolates, fly associated circular virus 2 (FlyACV-2) and cybaeus spider associated circular virus 2 (CySACV-2), representing members of the genus Gemykibivirus. CySACV-2 represents a novel gemykibivirus species, whereas FlyACV-2 is a variant (92\% genome-wide PI) of an unclassified species currently represented by a gemykibivirus isolate reported from pig feces (Nádia et al., 2017). Lastly, grasshopper associated circular virus 1 and tubeweb spider associated circular virus 1, represent two new species of the genus Gemykolovirus.

In addition to viral genomes that clearly fall within the well-established family Genomoviridae, we identified three genomes from fungus-farming termites that belong to a group of unclassified viruses that appear to be intermediate between genomoviruses and geminiviruses (Fig. 2). In a brief report noting the prevalence of these termite associated circular viruses (TACVs) in African Odontotermes sp. mounds we indicated that these genomes were most similar to members of the Genomoviridae (Kerr et al., 2018). However, Rep phylogenetic analysis indicate that only TACV-2 belongs to the Genomoviridae (genus Gemycirculovirus), while TACV-1, -3 , and -4 represent a new group of viruses. Furthermore, TACV-3 and -4 have top BLAST matches to geminiviruses (Table 3), but these genomes cluster closer to genomoviruses than geminiviruses (Fig. 2). There are a number of unclassified sequences retrieved from various environmental sources that fall in a similar phylogenetic position with TACV-1, -3 , and -4 , which may grant the formation of new taxonomic groups.

Members of the family Circoviridae, genus Cyclovirus, were detected in spiders $(n=2)$, flies $(n=1)$, and ants $(n=1)$ (Table 3$)$. Based on the species demarcation criteria of $80 \%$ genome-wide PI (Table 2), two of these genomes, arboreal ant associated circular virus 1 (AaACV-1) and soft spider associated circular virus 1 (SoSACV-1), represent novel cyclovirus species. Fly associated circular virus 1 (FlyACV-1) and spinybacked orbweaver circular virus 2 (SpOrbCV-2) are new isolates of the classified species cockroach associated cyclovirus 1 (CroACV-1) and dragonfly associated cyclovirus 3 (DfACyV-3), respectively. While FlyACV-1 seems to be a divergent variant of the CroACV-1 species, sharing 85\% genome-wide PI with this cyclovirus, SpOrbCV-2 shares 99\% PI with DfACyV-3. Interestingly, DfACyV-3 was discovered from a dragonfly collected in the same region in FL, USA (Rosario et al., 2012) as SpOrbCV-2, indicating that this cyclovirus species has been circulating in the region for at least 7 years. 


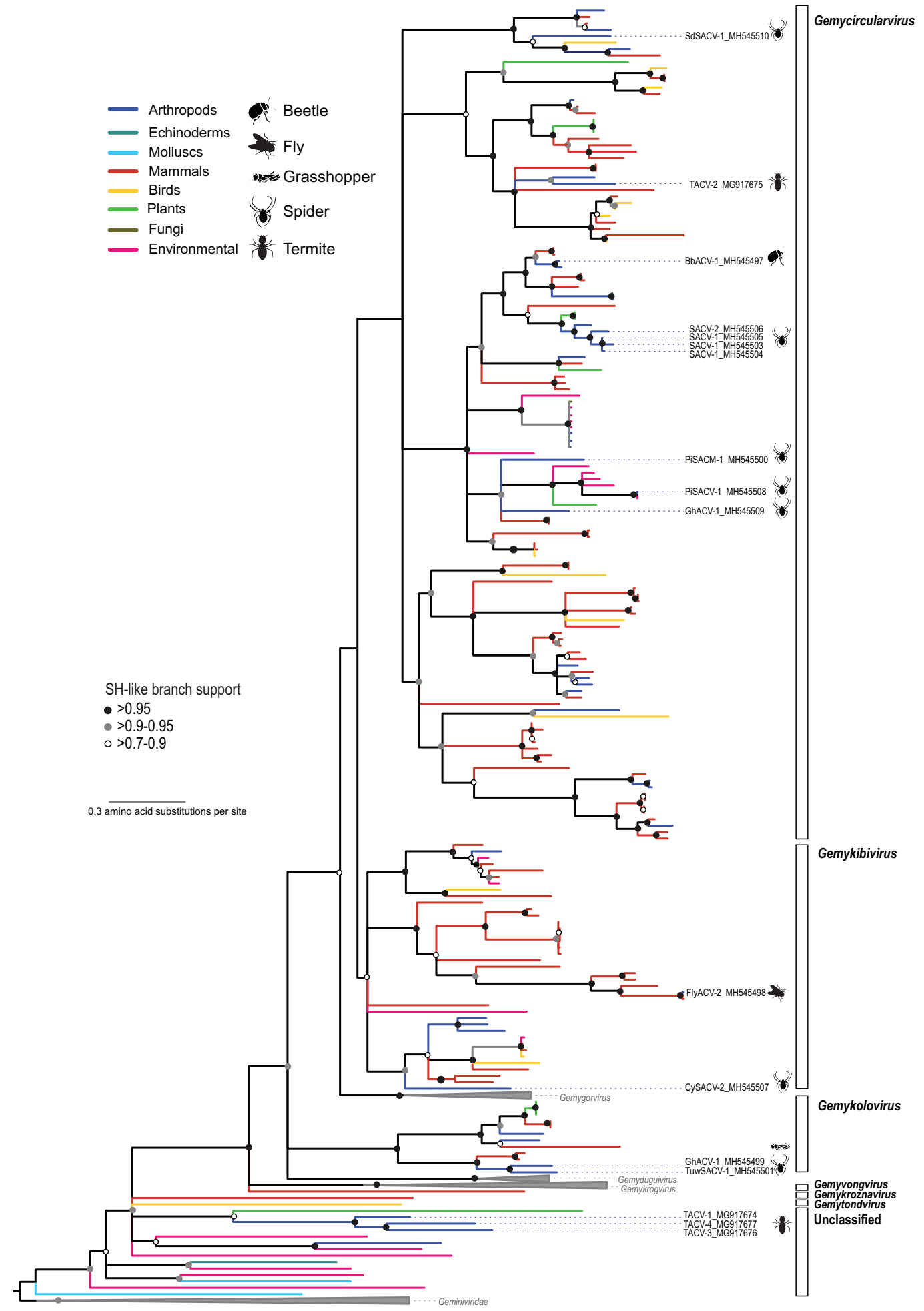


Figure 2 Maximum likelihood phylogenetic tree of replication-associated protein (Rep) amino acid sequences representing members of the family Genomoviridae and related CRESS DNA viruses. Branch colors distinguish sequences associated with various types of organisms and environmental sources. Bars on the right indicate clades representing genomovirus genera and unclassified sequences. Clades containing Rep sequences representing Gemygorvirus, Gemyduguivirus, and Gemykrogvirus species and members from the family Geminiviridae, which were used as an outgroup, were merged. Genomovirus Reps identified in this study are named and highlighted with schematics of terrestrial arthropods from which they were identified, including viruses associated with sierra dome spiders (SdSACV), pimoid spiders (PiSACV), tubeweb spiders (TuwSACV), grasshoppers (GhACV), and termites (TACV). Viruses identified in multiple species of spiders are identified as spider associated circular viruses (SACV). Branches with $<70 \%$ Shimodaira-Hasegawa (SH)-like support were collapsed. A version of the tree containing source information and accession numbers for all the sequences included in the phylogenetic analysis is available in Fig. S1. Arthropod silhouettes credit: Shutterstock vector library at https://www.shutterstock.com. Full-size $\underset{0}{0}$ DOI: $10.7717 /$ peerj.5761/fig-2

In addition to the four cycloviruses, we identified a genome, fly associated circular virus 5 (FlyACV-5), which is most closely related to cycloviruses and shares the genomic features characteristic of members in this genus, including genome organization, size, and putative ori (Table 3). Genome-wide PIs between FlyACV-5 and known cyclovirus species are within the accepted range for members of the Circoviridae ( $>55 \%$ genome-wide PIs) (Rosario et al., 2017). However, phylogenetic analysis of Rep sequences from members of the family Circoviridae did not support the placement of FlyACV-5 in either of the established genera for this family (Fig. 3). FlyACV-5 was most closely related to a CRESS DNA virus retrieved from bat feces, the Pacific flying fox feces associated circular DNA virus-8 (PfffACV-8, accession KT732825) (Male et al., 2016). Since both FlyACV-5 and PfffACV-8 have genomic features characteristic of the genus Cyclovirus and share genomewide PIs $>55 \%$ with members of this genus, these genomes may represent a novel group within the family Circoviridae. The phylogenetic analysis also revealed two cycloviruses, namely SoSACV-1 (accession MH545516) and Pacific flying fox feces associated circular DNA virus-2 (PfffACV-2, accession KT732786) that seem to be intermediate between circoviruses and cycloviruses (Fig. 3). However, at present, these genomes have been classified as cycloviruses based on their genome organization, which is a mirror image of that observed in circoviruses (Rosario et al., 2017).

Two new members of the family Smacoviridae were identified in flies (Table 3). Both isolates, fly associated circular viruses (FlyACV) -3 and -4 , represent new species belonging to the genus Porprismacovirus based on the species demarcation criteria (Table 2) and genus demarcation threshold of 40\% Rep amino acid sequence PI (Varsani \& Krupovic, 2018). Porprismacovirus is by far the genus with the highest number of species in the family (Varsani \& Krupovic, 2018). Although both FlyACV-3 and -4 represent new species, FlyACV-3 is closely related to an unclassified smacovirus isolated from macaque feces (Kapusinszky et al., 2017). Therefore, FlyACV-3 and the unclassified macaque associated smacovirus represent variants of the same Porprismacovirus species.

In addition to viruses most closely related to members of established CRESS DNA taxonomic groups, we identified an isolate representing a cricket-infecting virus that has not been classified. Cricket associated circular virus 1 (CrACV-1), identified in 


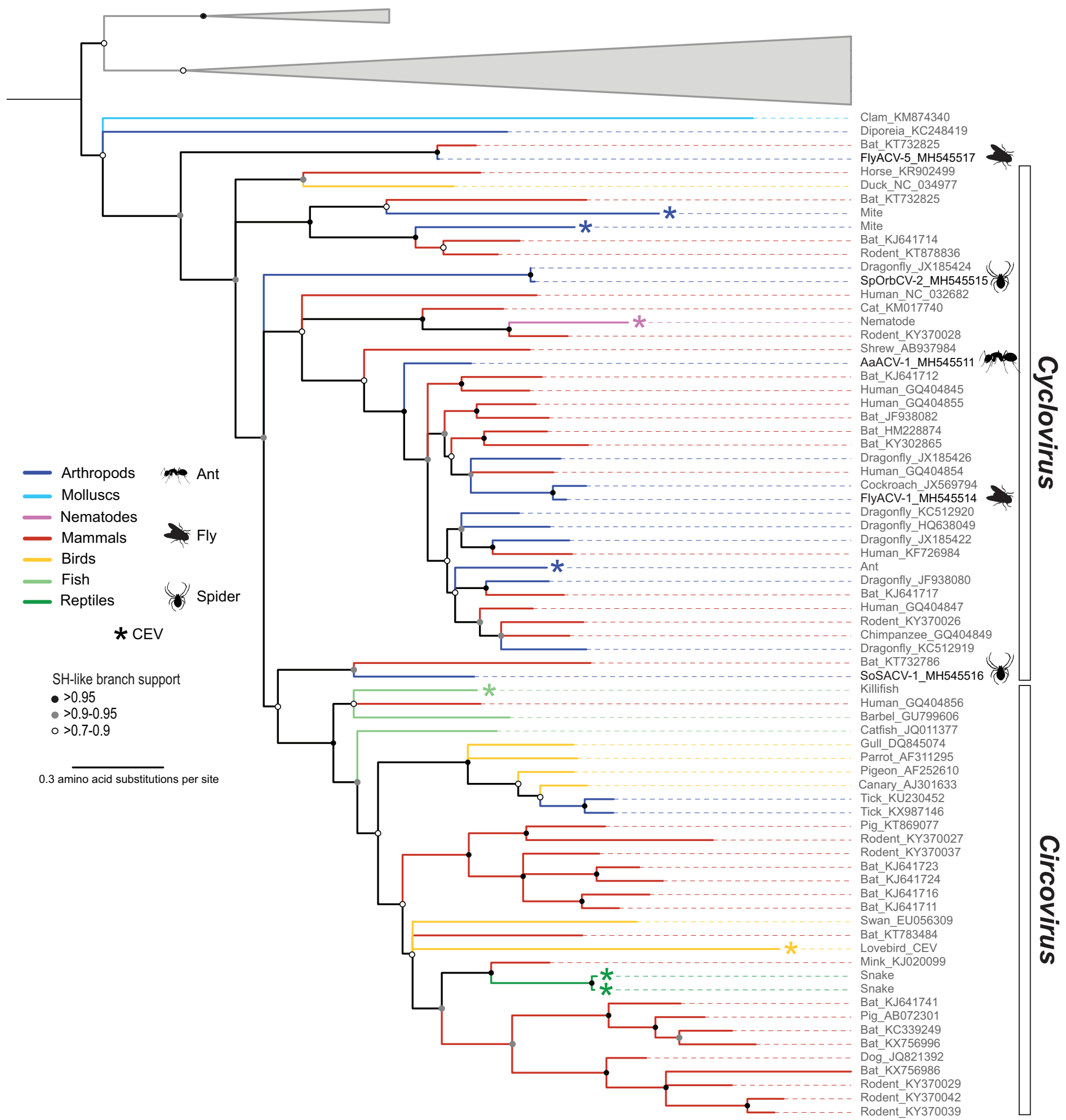


Figure 3 Midpoint rooted maximum likelihood phylogenetic tree of selected replication-associated protein (Rep) amino acid sequences representing members of the family Circoviridae and related CRESS DNA viruses. Branch colors distinguish sequences associated with various invertebrate and vertebrate organisms. Bars on the right indicate clades representing the Cyclovirus and Circovirus genera. Rep sequences representing CRESS DNA-like endogenous viral (CEV) elements are highlighted with an asterisk symbol. Cyclovirus Reps identified in this study are highlighted with schematics of terrestrial arthropods and include viruses identified from flies (FlyACV), ants (AaACV), soft spiders (SoSACV) and spinyback orbweavers (SpOrbCV). Reps representing unclassified genome sequences forming non-Circoviridae clades used as outgroups were merged and are highlighted in gray (accessions: KX246259, KR528563, KM598407, KR528546, KM874290, KM874319, KM874343, KT945164). Branches with $<70 \%$ Shimodaira-Hasegawa (SH)-like support were collapsed. Arthropod silhouettes credit: Shutterstock vector library at https://www.shutterstock.com. Full-size $\underline{0}$ DOI: 10.7717 /peerj.5761/fig-3

a store-bought cricket, represents an isolate of Achaeta domesticus volvovirus (Pham, Bergoin \& Tijssen, 2013a; Pham et al., 2013b). The four volvovirus genomes that have been reported to date, including CrACV-1, have been recovered from commercial crickets and share $>99 \%$ genome-wide PI, thus representing a single viral species.

\section{Detection of a cyclovirus endogenous element in a non-arthropod invertebrate}

Analysis of BLASTn matches for fly associated circular viruses (FlyACV) -6 and -7 in the GenBank non-redundant database revealed weak matches to nematodes. Although these initial BLAST matches were weak (query coverage $<15 \%$ ), this prompted a search in the WormBase Parasite database (Howe et al., 2017) using the FlyACVs putative Rep sequences as queries. This search led to the detection of a previously unreported CEV from Hymenolepis microstoma, commonly known as rodent tapeworm.

The H. micostoma CEV is embedded within a $251 \mathrm{~kb}$ genome scaffold (accession LN902886) (Tsai et al., 2013). The GenBank record for this genome scaffold noted two Rep-associated coding sequences (CDS) that were positioned next to each other. One of the CDS contains a near full-length Rep (accession CDS32196), whereas the second one (accession CDS32195) is interrupted at the SF3 Walker-A motif, at which point a partial capsid is encoded in the same reading frame. Inclusion of the near full-length Rep from H. microstoma in the phylogenetic analysis showed that this sequence falls within the Cyclovirus genus (Fig. 3). Although CEVs have been previously noted from parasitic helminths (Liu et al., 2011), this is the first cyclovirus CEV reported from nematodes. Notably, the H. microstoma CEV Rep sequence is most closely related to a cyclovirus sequence reported from rodents (accession KY370028). The putative endogenous capsid sequence is most similar to a cyclovirus reported from cat feces (Zhang et al., 2014), which is also closely related to the H. microstoma CEV and the rodent cyclovirus based on the Rep (Fig. 3). Therefore, both the CEV Rep and capsid sequences indicate that $H$. microstoma has been infected at some point by a cyclovirus. To our knowledge, this is the first evidence indicating that non-arthropod invertebrates serve as hosts for cycloviruses.

\section{DISCUSSION}

\section{Most CRESS DNA viral diversity circulates among arthropods and other invertebrates}

From the relatively small-scale survey presented here, it is clear that terrestrial arthropods harbor an extensive diversity of CRESS DNA viruses. Combining our results with previous 
reports, exogenous CRESS DNA viruses have now been reported in organisms from four out of the five major branches of the Arthropod Tree of Life (Giribet \& Edgecombe, 2012), including Euchelicerata (Class Arachnida) (Kraberger et al., 2018; Wang et al., 2018), Hexapoda (Class Insecta) (Dayaram et al., 2013, 2015b; Kraberger et al., 2017; Padilla-Rodriguez, Rosario \& Breitbart, 2013; Rosario et al., 2012; Tikhe \& Husseneder, 2017), Myriapoda (Class Diplopoda), and Crustacea (Classes Malacostraca, Maxillopoda, Copepoda, Branchiopoda) (Bistolas et al., 2017; Dunlap et al., 2013; Hewson et al., 2013b; Rosario et al., 2015a). To the best of our knowledge, no studies have specifically looked for CRESS DNA viruses within the remaining major arthropod branch, the Pycnogonida (sea spiders).

Spiders were identified as an unsuspected rich reservoir of CRESS DNA viral diversity, harboring most of the genomes from distinct viral groups identified in this survey. However, it should be noted that spiders are insectivores; thus, it is possible that the wide array of CRESS DNA viral diversity they contain is partially the result of accumulating CRESS DNA viruses from their insect prey. Similarly, a high diversity of CRESS DNA viruses has been reported from dragonflies, which are also top insect predators (Dayaram et al., 2013; Rosario et al., 2012). Since our methods might have recovered viruses from dietary content, it is possible that generalist arthropod predators may contain a broader range of CRESS DNA viruses than dietary specialists. Additionally, the discovery of some CRESS DNA viruses in multiple arthropod species may be due to overlapping diets. Phylogenetic analysis of the conserved Rep indicates that many of the diverse CRESS DNA viruses found within the terrestrial arthropods and other invertebrates fall outside established CRESS DNA viral families and do not form cohesive phylogenetic groups. This observation suggests that the CRESS DNA viral diversity associated with arthropods and other invertebrates has been grossly underestimated and that additional sampling of these groups would continue to expand the CRESS DNA virosphere. A more systematic survey targeting the same number of specimens from different taxonomic groups and representing a wider geographic distribution, rather than the opportunistic sampling effort shown here, may help elucidate which arthropod groups are hot spots for CRESS DNA viral diversity.

The diversity of CRESS DNA genomes identified in this study spans the entire CRESS DNA phylogenetic tree representing Reps recovered from a wide array of eukaryotic organisms (Fig. 1). Moreover, the CRESS DNA diversity falling outside established taxonomic groups that has been detected within arthropods and other invertebrates overwhelms the diversity reported from vertebrate organisms and plants, despite the fact that the latter groups have been heavily sampled. Members of the Alphasatellitidae, Geminiviridae, and Nanoviridae families were not detected in our survey, which did not include plant virus insect vectors. However, these plant-infecting CRESS DNA viruses and satellite molecules have long been known to circulate among hemipteran vectors (Hogenhout et al., 2008), which have been exploited to discover viral species found in a given area ( $\mathrm{Ng}$ et al., 2011; Rosario et al., 2015b, 2016). Therefore, arthropod-associated viruses include members from five out of the six CRESS DNA viral families that have been identified as monophyletic (Kazlauskas et al., 2017). The remaining established 
CRESS DNA family that was not identified in our survey, Bacilladnaviridae, includes viruses infecting unicellular algae and has only been reported from aquatic environments (Kazlauskas et al., 2017).

We identified novel viruses representing new members from the Genomoviridae, Smacoviridae, and Circoviridae families. Genomoviruses were the most diverse group, with 12 genomes recovered from spiders and insects from the orders Blattodea, Coleoptera, Diptera, and Orthoptera. The arthropod-associated genomoviruses represent at least three genera and highlight the ever growing diversity and wide distribution of this group of viruses (Krupovic et al., 2016). Two CRESS DNA viral sequences representing members of the Smacoviridae, which have been mainly recovered from feces from various mammals ( $\mathrm{Ng}$ et al., 2015; Steel et al., 2016; Varsani \& Krupovic, 2018), were recovered from blow flies (Diptera: Calliphoridae) collected in the Caribbean. The novel fly associated smacoviruses, FlyACV-3 and -4, were recovered from blow flies collected using a chicken carcass as bait (Yusseff-Vanegas \& Agnarsson, 2017). Since blow flies are known to feed on feces and tissues from various vertebrates, including mammals, it is likely that FlyACV-3 and -4 represent dietary content. Nevertheless, the detection of fly associated smacoviruses and a smacovirus in dragonflies (Dayaram et al., 2015b) indicates that this group of viruses circulates within arthropods.

Members of the family Circoviridae present a unique distribution relative to all of the other established CRESS DNA viral groups infecting multicellular organisms. All of the Circoviridae members identified in this study represent the genus Cyclovirus. Although cycloviruses have been identified in both vertebrates and arthropods, to date, members of the genus Circovirus have mainly been reported from the former. Moreover, this observation is consistent with CEV searches (Belyi, Levine \& Skalka, 2010; Dennis et al., in press; Liu et al., 2011) including a survey of more than 680 animal genomes, $\sim 50 \%$ of which were invertebrates (Dennis et al., 2018). Viruses reported from ticks are the only arthropod-associated CRESS DNA viruses belonging to the genus Circovirus (Tokarz et al., 2018; Wang et al., 2018). Since ticks are hematophagous parasites that feed exclusively on the blood of birds and mammals (Basu \& Charles, 2017), it is possible that tick associated circoviruses represent vertebrate-infecting viruses, in particular avian circoviruses (Fig. 3). Interestingly, bona fide circoviruses have not been reported from mosquitoes, a major group of blood-feeding arthropods of public health relevance. However, this might reflect the scarcity of mosquito DNA viromes reported to date. Despite these caveats, the available data suggests that cycloviruses circulate in a wide array of invertebrates and mammals, whereas circoviruses are mainly restricted to vertebrates and, perhaps, blood-feeding arthropod vectors.

In the Rep-based phylogeny, cycloviruses appear basal with respect to circoviruses (Fig. 3). Based on the higher diversity of cycloviruses described to date and the wider distribution of these viruses in both vertebrates and invertebrates, it is conceivable that cycloviruses are ancestral to circoviruses. We also note that there is a group of cycloviruses recovered from spiders and an insectivorous bat that seem intermediate between other cycloviruses and the circovirus clade (Fig. 3). Moreover, we detected viral sequences with cyclovirus genome organization from blow flies and an insectivorous bat that do not 
fall within the cyclovirus Rep clade that may represent a novel group within the Circoviridae. Further sampling of CRESS DNA viruses found in arthropods and other invertebrates may help resolve phylogenetic relationships among members of the Circoviridae. Nevertheless, our phylogenetic analysis supports the idea that there are distinct groups of cycloviruses (Dennis et al., 2018).

It appears that the complete phylogenetic breadth of CRESS DNA viral diversity that has been reported to date circulates within arthropods and other invertebrates, which is analogous to what has been noted for RNA viruses (Li et al., 2015; Shi et al., 2016a, 2018a). Few CRESS DNA Rep phylogenetic clusters are represented by viral sequences recovered from vertebrates, plants, or fungi alone (Fig. 1). This observation includes established CRESS DNA viral groups as well as novel sequences that have not been assigned to taxonomic groups. In addition, the vast majority of CRESS DNA sequences recovered from plants and fungi, including CEVs, fall near or within the closely related Geminiviridae and Genomoviridae clades. Vertebrate-associated CRESS DNA sequences that fall outside established groups have been mainly reported from fecal samples and most are intermixed with sequences that have been reported from invertebrates (Fig. 1). However, we identified one divergent clade that only included sequences from CRESS DNA viral isolates recovered from mammal feces and may represent a vertebrate-infecting lineage. More sampling, including blood or tissue samples as opposed to fecal samples, is needed to confirm this possibility. Despite the presence of plant-specific (Geminiviridae and Nanoviridae) and potentially vertebrate-specific viral lineages (genus Circovirus), most of the CRESS DNA viral diversity identified in vertebrates, plants and fungi is nested within the much broader genetic diversity of invertebrate-associated viruses.

\section{Related CRESS DNA viruses identified in disparate organisms}

The phylogenetic analysis revealed many Rep sequences from disparate sources grouping together in the same clade (Fig. 1). Even when looking at broad source classifications, such as vertebrates, plants, arthropods and other invertebrates, few of the clades that fall outside of the established CRESS DNA viral groups represent isolates retrieved from similar sources. Moreover, the same "source intermixing" can be observed within established CRESS DNA groups (Figs. 2 and 3). CRESS DNA viral isolates representing members of the Genomoviridae are a notable example. Genomovirus genomes have been recovered from plants, fungi, vertebrates and arthropods; however, there is no clear separation of genomovirus groups based on the source (Fig. 2; Fig. S1). With such phylogenetic distribution, it is tempting to speculate about potential cross-species CRESS DNA virus transmission. However, since many CRESS DNA viruses have been identified through molecular assays alone, it is difficult to predict the host for most of these viruses, including those that fall within established CRESS DNA groups. Therefore, we cannot make inferences regarding horizontal CRESS DNA virus transmission. Furthermore, cross-species transmission between arthropod and vertebrate-infecting viruses has been deemed unlikely (Dennis et al., 2018). Nevertheless, available data suggest that closely related CRESS DNA viruses circulate among disparate organisms, 
providing opportunities for cross-viral species interactions that may lead to recombination and the emergence of new viral species (Krupovic, 2013; Roux et al., 2013).

The detection of related CRESS DNA viruses in disparate eukaryotic organisms might be partly explained by vectored viruses and/or viruses infecting hosts that interact closely with other species in a similar niche. The two CRESS DNA viral families whose members infect plants and were not identified in our survey, namely Geminiviridae and Nanoviridae, are transmitted by hemipteran vectors where these viruses may be found in high titers (Czosnek et al., 2017; Watanabe \& Bressan, 2013). In contrast to arthropod-borne animal-infecting RNA viruses and some vectored plant RNA viruses, it is thought that CRESS DNA plant viruses do not replicate or express genes in their vector (i.e., non-propagative transmission) (Dietzgen, Mann \& Johnson, 2016).

However, there is evidence showing genetic changes of a nanovirus within its aphid vector (Sicard et al., 2015). Moreover, some begomoviruses (family Geminiviridae) can replicate within their whitefly vector (Czosnek et al., 2017) and alter the whitefly feeding behavior to result in enhanced virus transmission (Liu et al., 2013). Therefore, there is evidence for complex cross-kingdom interactions between plant-infecting CRESS DNA viruses and their insect vectors.

In addition to recognized interactions between plant-infecting CRESS DNA viruses and their hemipteran vectors, CRESS DNA viruses may be present in systems where cross-kingdom species interactions are intertwined. We discovered CRESS DNA viruses in organisms that have been previously investigated for their role in model symbiosis systems, including fungus-insect and plant-insect systems. Interestingly, CRESS DNA viruses discovered in both fungus-farming insects investigated here, including bark beetle associated circular virus $1(\mathrm{BbACV}-1)$ and TACVs, were most closely related to members of the Genomoviridae (Fig. 2). Infection assays with Sclerotinia sclerotiorum hypovirulence-associated DNA virus 1 (SsHADV-1), the only genomovirus with a confirmed host (Yu et al., 2010), suggest that some genomoviruses are able to infect both fungi and insects. The primary SsHADV-1 host is a plant fungal pathogen; however, the virus is able to replicate in a mycophagous insect that it potentially uses as a transmission mechanism (Liu et al., 2016). Although we are not able to discern if BbACV-1 and TACVs infect either the farmer (insect) or the crop (fungus) in these ancient agricultural systems (Mueller \& Gerardo, 2002), their discovery provides two additional examples where genomovirus-insect-fungi interactions are tightly connected.

Another notable example is the novel AaACV-1 cyclovirus, which was identified multiple times in all three ant species tested from the whistling thorn (Vachellia (Acacia) drepanolobium) ant-plant system in East Africa, with genomes recovered from each ant species sharing $>98 \%$ PI. The three ant species tested (Tetraponera penzigi, Crematogaster nigriceps, and Crematogaster mimosae) live in an obligate mutualism with the acacia tree throughout its range (Young, Stubblefield \& Isbell, 1997), protecting their host plants from mammalian herbivores, but also shaping aspects of the host environment such as plant-associated fungal communities, in a species-specific manner (Baker et al., 2017). Although the ants inhabit domatia (arthropod-occupied chambers) of the same acacia tree 
species, each tree typically hosts a single colony at any point in time (Palmer et al., 2000). Opportunities for direct viral transmission between colonies of the same or different species are therefore likely to be restricted to infrequent antagonistic interactions between colonies occupying neighboring trees, so we did not expect to discover the same AaACV-1 virus in all three ant species. On the other hand, each tree typically hosts multiple colonies sequentially over its lifetime, providing the ants with shelter in domatia and food in the form of extrafloral nectar. The common host plant thus represents a good candidate mechanism for the circulation of AaACV-1 in these three different ant species. It remains to be determined what role, if any, AaACV-1 infection plays in this system. Interestingly, an endogenous cylcovirus Rep has been identified in another arboreal ant (Pseudomyrmex gracilis) (Fig. 3) (Dennis et al., 2018) suggesting that cycloviruses may be common in complex ant-plant symbiotic systems (Clement et al., 2008).

\section{Genomic fossil record supports widespread distribution of CRESS DNA viruses among invertebrates}

Evidence from CEVs supports that CRESS DNA viruses infect or have infected a diversity of organisms, including hosts from four of the five supergroups of eukaryotes (Belyi, Levine \& Skalka, 2010; Dennis et al., in press, 2018; Liu et al., 2011). Here, we took advantage of previously reported CEVs and put them in a phylogenetic context with extant exogenous CRESS DNA viruses recovered from a wide array of organisms. Analyzed CEVs only included Rep sequences that were over 200 amino acids in length and did not contain any early stop codons or frameshifts. Therefore, analyzed CEVs potentially represent relatively recent CRESS DNA viral infections or functional elements co-opted by the host (Dennis et al., 2018; Liu et al., 2011). Notably, a CEV identified in the germline of the brown recluse spider Loxosceles reclusa (sequence ID: CVe. Loxosceles_reclusa.7, Dennis et al., 2018) is most closely related to the longjawed orbweaver circular virus 2 (LjOrbCV-2, accession MH545529) identified here, suggesting that viruses similar to LjOrbCV-2 infect spiders. Interestingly, all of the CEVs reported from vertebrates clustered within the genus Circovirus, whereas those reported from invertebrates were distributed across the CRESS DNA Rep phylogenetic tree (Fig. 1). Similarly, CEVs found in fungal genomes clustered near the Genomoviridae and Geminiviridae clades. Therefore, the available CEV data support that CRESS DNA viruses infecting vertebrates, plants, and fungi show a limited phylogenetic distribution compared to viruses found in invertebrates.

CRESS DNA-like endogenous viral sequences have revealed multiple insertions from related as well as distinct CRESS DNA viruses in various vertebrate host germlines (Dennis et al., in press). Multiple CEVs have also been reported from the same invertebrate species, with up to 19 sequences identified in a given host (Dennis et al., 2018) and our phylogenetic analysis supports that divergent CRESS DNA viruses can infect the same invertebrate host species (Fig. 1). For example, we were able to include in our analysis seven distinct Rep sequences previously identified as CEVs from brine flies (genus Ephydra) (Dennis et al., 2018), representing two species, E. hidrans $(n=5)$

and E. gracilis $(n=2)$. Surprisingly, none of the endogenized Rep sequences from brine 
flies clustered close to each other. The closest phylogenetic neighbors to Ephydra Rep CEVs have been primarily recovered from aquatic invertebrates perhaps reflecting the ecology of these unique dipterans (Class Insecta) that live at the interface between aquatic and terrestrial habitats. Brine flies live in hypersaline alkaline lakes feeding on benthic algae and, whereas the larval stages are underwater, adults are considered terrestrial (Herbst, 1980). Note that one of the Ephydra CEVs clustered with a Rep representing a CRESS DNA virus recovered from another dipteran in its terrestrial phase (mosquitoes).

CRESS DNA-like endogenous viral sequences identified in parasitic invertebrates, including protozoans and nematodes, also demonstrate infection by distinct CRESS DNA elements. The presence of Rep-like sequences in the genomes of enteric protozoan parasites, including Giardia and Entamoeba, were noted more than 10 years ago (Gibbs et al., 2006). Further investigation of CEVs from these parasites showed that various Rep elements are transcribed, at least in E. histolytica, suggesting that the Rep has been co-opted for the benefit of the parasite (Liu et al., 2011). We were able to include seven Rep CEVs previously detected in Giardia intestinalis $(n=2)$ (Gibbs et al., 2006) and three species of Entamoeba $(n=5)$ (Fig. 1) (Liu et al., 2011). The two analyzed Rep sequences from Giardia clustered together, whereas sequences from E. histolytica clustered in two groups. Therefore, the unicellular parasite E. histolytica has been infected by at least two distinct CRESS DNA elements. Although we were not able to include multiple CEVs from the same nematode species, three out of four CEVs from parasitic nematodes clustered together, suggesting that there is a nematode-infecting lineage of CRESS DNA viruses or at least an ancestral one. Notably, extrachromosomal virus-like elements encoding a Rep have been reported from a free-living freshwater nematode (Rebrikov et al., 2002) and, thus, CRESS DNA-like elements may be more common in nematodes than previously recognized.

Circular Rep-encoding ssDNA viral infection of parasitic organisms transmitted through the fecal-oral route further exemplify the difficulties associated with predicting potential hosts for viruses identified in feces. There is a possibility that CRESS DNA viral sequences identified in vertebrate feces actually represent parasite-infecting CRESS DNA viruses since some parasites are ubiquitous and can be found in high numbers in fecal matter (Oates et al., 2012). For example, three of the CEVs from enteric protozoan parasites clustered close to CRESS DNA viral sequences retrieved from mammal feces (Fig. 1). Two of these were Giardia CEVs that clustered with FlyACV-6 and -7 identified here and rodent associated viruses (Phan et al., 2011). Since blow flies feed on fecal matter, FlyACV-6 and -7 may represent ingested viruses from feces that may infect either rodents or a parasitic protozoan host. Similarly, we detected a CEV in a rodent-infecting parasitic tapeworm, H. microstoma, whose Rep was most similar to cycloviruses recovered from rodents and cat feces (Fig. 3). With the available information, it is difficult to establish if the cat and rodent associated cycloviruses infect these mammals or co-occurring parasitic organisms. Alternatively, it is an intriguing possibility that parasitic eukaryotes can act as CRESS DNA viral vectors, which would result in tightly connected CRESS DNA virus-eukaryotic parasite-host interactions. 
The detection of CEVs in a wide diversity of parasitic eukaryotes, including nematodes, protozoans, and arthropods indicates that the role of parasitic organisms in CRESS DNA viral ecology and evolution should be explored. Moreover, there are extant exogenous CRESS DNA viruses circulating in ectoparasitic arachnids (mites and ticks) (Kraberger et al., 2018; Tokarz et al., 2018; Waits et al., 2018; Wang et al., 2018).

The detection of divergent RNA viruses in parasitic nematodes has also highlighted the need to further investigate the role of parasites in virus evolution (Shi et al., 2016a). The scarcity of data regarding parasite-associated microbes, including viruses, has been recognized and efforts are underway to try to address this knowledge gap (Dheilly et al., 2017). Exploration of undersampled invertebrate taxa and non-fecal samples from vertebrates will certainly provide more insights into the evolution of CRESS DNA viruses. In turn, the discovery of divergent CRESS DNA viruses will inform efforts investigating the genomic fossil record to better understand viral evolution and host biology (Feschotte \& Gilbert, 2012; Krupovic \& Forterre, 2015).

\section{CONCLUSION}

Here, we described CRESS DNA viruses from terrestrial arthropods with a widespread phylogenetic distribution, including members of yet unclassified viral groups.

The cosmopolitan distribution of CRESS DNA viruses, combined with the dynamic nature of these viruses, which seem to commonly exchange genetic information (Kazlauskas, Varsani \& Krupovic, 2018; Quaiser et al., 2016), may help explain the unprecedented diversity recognized within recent years. It is important to note that our analysis underestimates the diversity within CRESS DNA viral genomes since we only included genome sequences associated with specific organisms, as opposed to environments (e.g., sewage, seawater), which would have added more than 200 Rep sequences to our phylogeny. In spite of this, it is clear that arthropods and other invertebrates harbor an extensive diversity of CRESS DNA viruses that dwarfs the genomic diversity observed in vertebrates, plants, and fungi. CRESS DNA viruses are emerging as a dominant and diverse group in the eukaryotic DNA viral world, with each report of novel genomes expanding the boundaries of this group. In contrast to other eukaryotic DNA viruses, CRESS DNA viruses are associated with a wide range of organisms across the tree of life, reflecting their ancient evolutionary history. Viral discovery efforts in undersampled taxa promise to reveal a more complete view of CRESS DNA virus diversity that will elucidate evolutionary linkages among these successful "genetic parasites" (Koonin \& Dolja, 2014).

\section{ACKNOWLEDGEMENTS}

We would like to thank students (Class of 2019) from the Laura Mercado Specialized School of Agro-ecology in San Germán, Puerto Rico for enthusiastically collecting specimens for this project during an outreach activity and Dr. José L. Agosto from the University of Puerto Rico, Río Piedras Campus for his assistance in conducting this activity. We also acknowledge Rachel C. Harbeitner, Dawn B. Goldsmith, Allison Cohen, Parker E. Jernigan, Sidney Fulford, and Carina Graham for their help with sample 
processing. Thanks to Naomi E. Pierce (Harvard University) and Jon G. Sanders (University of California, San Diego) for facilitating access to ant samples from Kenya. Thanks to the CarBio team (http://www.islandbiogeography.org/participants.html) for their help collecting blow fly samples in the Caribbean.

\section{ADDITIONAL INFORMATION AND DECLARATIONS}

\section{Funding}

This work was funded through NSF Assembling the Tree of Life Program grant DEB-1239976 to Karyna Rosario and Mya Breitbart. Field work for blow fly collections in the Caribbean was funded through NSF grants DEB-1314749 and DEB-1050253 to Ingi Agnarsson and Greta Binford from the University of Vermont and Lewis \& Clark College, respectively (Principal Investigators for Sohath Z Yusseff-Vanegas). Fungus-farming termites and ant samples from Africa were collected in the course of fieldwork funded by NSF grant DEB-1355122 to Corina Tarnita and Robert Pringle from Princeton University (Principal Investigators for Christopher CM Baker). The funders had no role in study design, data collection and analysis, decision to publish, or preparation of the manuscript.

\section{Grant Disclosures}

The following grant information was disclosed by the authors:

NSF Assembling the Tree of Life Program grant: DEB-1239976.

Blow fly collection in the Caribbean was funded through NSF grants: DEB-1314749 and DEB-1050253.

University of Vermont and Lewis \& Clark College.

Ant and termite collections in Africa were funded by NSF grant: DEB-1355122.

\section{Competing Interests}

Mya Breitbart is an Academic Editor for PeerJ.

\section{Author Contributions}

- Karyna Rosario conceived and designed the experiments, performed the experiments, analyzed the data, prepared figures and/or tables, authored or reviewed drafts of the paper, approved the final draft.

- Kaitlin A. Mettel performed the experiments, approved the final draft.

- Bayleigh E. Benner performed the experiments, approved the final draft.

- Ryan Johnson performed the experiments, approved the final draft.

- Catherine Scott contributed reagents/materials/analysis tools, approved the final draft.

- Sohath Z. Yusseff-Vanegas contributed reagents/materials/analysis tools, approved the final draft.

- Christopher C.M. Baker contributed reagents/materials/analysis tools, approved the final draft.

- Deby L. Cassill contributed reagents/materials/analysis tools, approved the final draft.

- Caroline Storer contributed reagents/materials/analysis tools, approved the final draft. 
- Arvind Varsani analyzed the data, prepared figures and/or tables, approved the final draft.

- Mya Breitbart conceived and designed the experiments, analyzed the data, prepared figures and/or tables, approved the final draft.

\section{Data Availability}

The following information was supplied regarding data availability:

The genomes and replicons described here are accessible via GenBank accession numbers: MG917674 to MG917677 and MH545497 to MH545543.

\section{Supplemental Information}

Supplemental information for this article can be found online at http://dx.doi.org/10.7717/ peer.5761\#supplemental-information.

\section{REFERENCES}

Altschul SF, Gish W, Miller W, Myers EW, Lipman DJ. 1990. Basic local alignment search tool. Journal of Molecular Biology 215(3):403-410 DOI 10.1016/s0022-2836(05)80360-2.

Baker CCM, Martins DJ, Pelaez JN, Billen JPJ, Pringle A, Frederickson ME, Pierce NE. 2017. Distinctive fungal communities in an obligate African ant-plant mutualism. Proceedings of the Royal Society B: Biological Sciences 284(1850):20162501 DOI 10.1098/rspb.2016.2501.

Basu AK, Charles RA. 2017. Chapter 1-A general account of ticks. Ticks of Trinidad and Tobago-an overview. London: Academic Press, 1-33.

Belyi VA, Levine AJ, Skalka AM. 2010. Sequences from ancestral single-stranded DNA viruses in vertebrate genomes: the Parvoviridae and Circoviridae are more than 40 to 50 million years old. Journal of Virology 84(23):12458-12462 DOI 10.1128/Jvi.01789-10.

Bettarel Y, Halary S, Auguet J-C, Mai TC, Van Bui N, Bouvier T, Got P, Bouvier C, Monteil-Bouchard S, Christelle D. 2018. Corallivory and the microbial debacle in two branching scleractinians. ISME Journal 12:1109-1126 DOI 10.1038/s41396-017-0033-5.

Bistolas K, Besemer R, Rudstam L, Hewson I. 2017. Distribution and inferred evolutionary characteristics of a chimeric ssDNA virus associated with intertidal marine isopods. Viruses 9(12):361 DOI 10.3390/v9120361.

Briddon RW, Martin DP, Roumagnac P, Navas-Castillo J, Fiallo-Olivé E, Moriones E, Lett J-M, Zerbini FM, Varsani A. 2018. Alphasatellitidae: a new family with two subfamilies for the classification of geminivirus- and nanovirus-associated alphasatellites. Archives of Virology 163(9):2587-2600 DOI 10.1007/s00705-018-3854-2.

Brown JK, Zerbini FM, Navas-Castillo J, Moriones E, Ramos-Sobrinho R, Silva JF, Fiallo-Olivé E, Briddon R, Hernández-Zepeda C, Idris A, Malathi VG, Martin D, Rivera-Bustamante R, Ueda S, Varsani A. 2015. Revision of Begomovirus taxonomy based on pairwise sequence comparisons. Archives of Virology 160(6):1593-1619

DOI 10.1007/s00705-015-2398-y.

Buck CB, Van Doorslaer K, Peretti A, Geoghegan EM, Tisza MJ, An P, Katz JP, Pipas JM, McBride AA, Camus AC, McDermott AJ, Dill JA, Delwart E, Ng TFF, Farkas K, Austin C, Kraberger S, Davison W, Pastrana DV, Varsani A. 2016. The ancient evolutionary history of polyomaviruses. PLOS Pathogens 12(4):e1005574 DOI 10.1371/journal.ppat.1005574.

Burge C, Karlin S. 1997. Prediction of complete gene structures in human genomic DNA. Journal of Molecular Biology 268(1):78-94 DOI 10.1006/jmbi.1997.0951. 
Clement LW, Koppen SC, Brand WA, Heil M. 2008. Strategies of a parasite of the ant-Acacia mutualism. Behavioral Ecology and Sociobiology 62(6):953-962

DOI 10.1007/s00265-007-0520-1.

Czosnek H, Hariton-Shalev A, Sobol I, Gorovits R, Ghanim M. 2017. The incredible journey of begomoviruses in their whitefly vector. Viruses 9(10):273 DOI 10.3390/v9100273.

Dayaram A, Goldstien S, Argüello-Astorga GR, Zawar-Reza P, Gomez C, Harding JS, Varsani A. 2015a. Diverse small circular DNA viruses circulating amongst estuarine molluscs. Infection, Genetics and Evolution 31:284-295 DOI 10.1016/j.meegid.2015.02.010.

Dayaram A, Potter KA, Moline AB, Rosenstein DD, Marinov M, Thomas JE, Breitbart M, Rosario K, Arguello-Astorga GR, Varsani A. 2013. High global diversity of cycloviruses amongst dragonflies. Journal of General Virology 94(Pt_8):1827-1840 DOI 10.1099/vir.0.052654-0.

Dayaram A, Potter KA, Pailes R, Marinov M, Rosenstein DD, Varsani A. 2015b. Identification of diverse circular single-stranded DNA viruses in adult dragonflies and damselflies (Insecta: Odonata) of Arizona and Oklahoma, USA. Infection, Genetics and Evolution 30:278-287 DOI 10.1016/j.meegid.2014.12.037.

Dennis TPW, De Souza WM, Marsile-Medun S, Singer JB, Wilson SJ, Gifford RJ. The evolution, distribution and diversity of endogenous circoviral elements in vertebrate genomes. Virus Research (in press) DOI 10.1016/j.virusres.2018.03.014.

Dennis TPW, Flynn PJ, Marciel De Souza W, Singer JB, Moreau CS, Wilson SJ, Gifford RJ. 2018. Insights into circovirus host range from the genomic fossil record. Journal of Virology 92(16):e00145-18 DOI 10.1128/jvi.00145-18.

Dheilly NM, Bolnick D, Bordenstein S, Brindley PJ, Figueres C, Holmes EC, Martinez Martinez J, Phillips AJ, Poulin R, Rosario K. 2017. Parasite microbiome project: systematic investigation of microbiome dynamics within and across parasite-host interactions. mSystems 2(4):e00050-17 DOI 10.1128/mSystems.00050-17.

Diemer G, Stedman KM. 2012. A novel virus genome discovered in an extreme environment suggests recombination between unrelated groups of RNA and DNA viruses. Biology Direct 7(1):13 DOI 10.1186/1745-6150-7-13.

Dietzgen RG, Mann KS, Johnson KN. 2016. Plant virus-insect vector interactions: current and potential future research directions. Viruses 8(11):303 DOI 10.3390/v8110303.

Dolja VV, Koonin EV. 2018. Metagenomics reshapes the concepts of RNA virus evolution by revealing extensive horizontal virus transfer. Virus Research 244:36-52 DOI 10.1016/j.virusres.2017.10.020.

Duffy S, Holmes EC. 2009. Validation of high rates of nucleotide substitution in geminiviruses: phylogenetic evidence from East African cassava mosaic viruses. Journal of General Virology 90(6):1539-1547 DOI 10.1099/vir.0.009266-0.

Duffy S, Shackelton LA, Holmes EC. 2008. Rates of evolutionary change in viruses: patterns and determinants. Nature Reviews Genetics 9(4):267-276 DOI 10.1038/nrg2323.

Dunlap DS, Ng TFF, Rosario K, Barbosa JG, Greco AM, Breitbart M, Hewson I. 2013. Molecular and microscopic evidence of viruses in marine copepods. Proceedings of the National Academy of Sciences of the United States of America 110(4):1375-1380 DOI 10.1073/pnas.1216595110.

Edgar RC. 2004. MUSCLE: multiple sequence alignment with high accuracy and high throughput. Nucleic Acids Research 32(5):1792-1797 DOI 10.1093/Nar/Gkh340.

Feschotte C, Gilbert C. 2012. Endogenous viruses: insights into viral evolution and impact on host biology. Nature Reviews Genetics 13(4):283-296 DOI 10.1038/nrg3199. 
Firth C, Charleston MA, Duffy S, Shapiro B, Holmes EC. 2009. Insights into the evolutionary history of an emerging livestock pathogen: porcine circovirus 2. Journal of Virology 83(24):12813-12821 DOI 10.1128/Jvi.01719-09.

Folmer O, Black M, Hoeh W, Lutz R, Vrijenhoek R. 1994. DNA primers for amplification of mitochondrial cytochrome c oxidase subunit I from diverse metazoan invertebrates. Molecular Marine Biology and Biotechnology 3(5):294-299.

Fu L, Niu B, Zhu Z, Wu S, Li W. 2012. CD-HIT: accelerated for clustering the next-generation sequencing data. Bioinformatics 28(23):3150-3152 DOI 10.1093/bioinformatics/bts565.

Geoghegan JL, Holmes EC. 2017. Predicting virus emergence amid evolutionary noise. Open Biology 7(10):170189 DOI 10.1098/rsob.170189.

Gibbs MJ, Smeianov VV, Steele JL, Upcroft P, Efimov BA. 2006. Two families of Rep-like genes that probably originated by interspecies recombination are represented in viral, plasmid, bacterial, and parasitic protozoan genomes. Molecular Biology and Evolution 23(6):1097-1100 DOI 10.1093/molbev/msj122.

Giribet G, Edgecombe GD. 2012. Reevaluating the arthropod tree of life. Annual Review of Entomology 57(1):167-186 DOI 10.1146/annurev-ento-120710-100659.

Gronenborn B. 2004. Nanoviruses: genome organisation and protein function. Veterinary Microbiology 98(2):103-109 DOI 10.1016/j.vetmic.2003.10.015.

Guindon S, Dufayard J-F, Lefort V, Anisimova M, Hordijk W, Gascuel O. 2010. New algorithms and methods to estimate maximum-likelihood phylogenies: assessing the performance of PhyML 3.0. Systematic Biology 59(3):307-321 DOI 10.1093/sysbio/syq010.

Haible D, Kober S, Jeske H. 2006. Rolling circle amplification revolutionizes diagnosis and genomics of geminiviruses. Journal of Virological Methods 135(1):9-16 DOI 10.1016/j.jviromet.2006.01.017.

Herbst DB. 1980. Ecological physiology of the larvel brine fly Ephydra (Hydropyrus) hians, and alkaline-salt lake inhabiting Ephyrid (Diptera). Corvallis: Oregon State University.

Hewson I, Eaglesham JB, Höök TO, LaBarre BA, Sepúlveda MS, Thompson PD, Watkins JM, Rudstam LG. 2013a. Investigation of viruses in Diporeia spp. from the Laurentian Great Lakes and Owasco Lake as potential stressors of declining populations. Journal of Great Lakes Research 39(3):499-506 DOI 10.1016/j.jglr.2013.06.006.

Hewson I, Ng G, Li W, LaBarre BA, Aguirre I, Barbosa JG, Breitbart M, Greco AW, Kearns CM, Looi A, Schaffner LR, Thompson PD, Hairston NG. 2013b. Metagenomic identification, seasonal dynamics, and potential transmission mechanisms of aDaphnia-associated singlestranded DNA virus in two temperate lakes. Limnology and Oceanography 58:1605-1620 DOI 10.4319/lo.2013.58.5.1605.

Hogenhout SA, Ammar ED, Whitfield AE, Redinbaugh MG. 2008. Insect vector interactions with persistently transmitted viruses. Annual Review of Phytopathology 46(1):327-359 DOI 10.1146/annurev.phyto.022508.092135.

Howe KL, Bolt BJ, Shafie M, Kersey P, Berriman M. 2017. WormBase ParaSite-a comprehensive resource for helminth genomics. Molecular and Biochemical Parasitology 215:2-10 DOI 10.1016/j.molbiopara.2016.11.005.

Kapusinszky B, Ardeshir A, Mulvaney U, Deng X, Delwart E. 2017. Case control comparison of enteric viromes in captive rhesus macaques with acute or idiopathic chronic diarrhea. Journal of Virology 91(18):e00952-17 DOI 10.1128/jvi.00952-17.

Kazlauskas D, Dayaram A, Kraberger S, Goldstien S, Varsani A, Krupovic M. 2017. Evolutionary history of ssDNA bacilladnaviruses features horizontal acquisition of the capsid gene from ssRNA nodaviruses. Virology 504:114-121 DOI 10.1016/j.virol.2017.02.001. 
Kazlauskas D, Varsani A, Krupovic M. 2018. Pervasive chimerism in the replication-associated proteins of uncultured single-stranded DNA viruses. Viruses 10(4):187 DOI 10.3390/v10040187.

Kerr M, Rosario K, Baker CCM, Breitbart M. 2018. Discovery of four novel circular single-stranded DNA viruses in fungus-farming termites. Genome Announcements 6(17):e00318 DOI 10.1128/genomeA.00318-18.

Kim KH, Bae JW. 2011. Amplification methods bias metagenomic libraries of uncultured single-stranded and double-stranded DNA viruses. Applied and Environmental Microbiology 77(21):7663-7668 DOI 10.1128/Aem.00289-11.

Kim KH, Chang HW, Nam YD, Roh SW, Kim MS, Sung Y, Jeon CO, Oh HM, Bae JW. 2008. Amplification of uncultured single-stranded DNA viruses from rice paddy soil. Applied and Environmental Microbiology 74(19):5975-5985 DOI 10.1128/aem.01275-08.

Koonin EV, Dolja VV. 2014. Virus world as an evolutionary network of viruses and capsidless selfish elements. Microbiology and Molecular Biology Reviews 78(2):278-303 DOI 10.1128/mmbr.00049-13.

Koonin EV, Dolja VV, Krupovic M. 2015. Origins and evolution of viruses of eukaryotes: the ultimate modularity. Virology 479-480:2-25 DOI 10.1016/j.virol.2015.02.039.

Kraberger S, Argüello-Astorga GR, Greenfield LG, Galilee C, Law D, Martin DP, Varsani A. 2015. Characterisation of a diverse range of circular replication-associated protein encoding DNA viruses recovered from a sewage treatment oxidation pond. Infection, Genetics and Evolution 31:73-86 DOI 10.1016/j.meegid.2015.01.001.

Kraberger S, Polston JE, Capobianco HM, Alcalá-Briseño RI, Fontenele RS, Varsani A. 2017. Genomovirus genomes recovered from Echinothrips americanus sampled in Florida, USA. Genome Announcements 5(21):e00445-17 DOI 10.1128/genomeA.00445-17.

Kraberger S, Visnovsky GA, Van Toor RF, Male MF, Waits K, Fontenele RS, Varsani A. 2018. Genome sequences of two single-stranded DNA viruses identified in Varroa destructor. Genome Announcements 6(9):e00107-18 DOI 10.1128/genomeA.00107-18.

Krupovic M. 2013. Networks of evolutionary interactions underlying the polyphyletic origin of ssDNA viruses. Current Opinion in Virology 3(5):578-586 DOI 10.1016/j.coviro.2013.06.010.

Krupovic M, Forterre P. 2015. Single-stranded DNA viruses employ a variety of mechanisms for integration into host genomes. Annals of the New York Academy of Sciences 1341(1):41-53 DOI 10.1111/nyas.12675.

Krupovic M, Ghabrial SA, Jiang DH, Varsani A. 2016. Genomoviridae: a new family of widespread single-stranded DNA viruses. Archives of Virology 161(9):2633-2643 DOI 10.1007/s00705-016-2943-3.

Krupovic M, Zhi N, Li J, Hu G, Koonin EV, Wong S, Shevchenko S, Zhao K, Young NS. 2015. Multiple layers of chimerism in a single-stranded DNA virus discovered by deep sequencing. Genome Biology and Evolution 7(4):993-1001 DOI 10.1093/gbe/evv034.

Kumar S, Stecher G, Tamura K. 2016. MEGA7: molecular evolutionary genetics analysis version 7.0 for bigger datasets. Molecular Biology and Evolution 33(7):1870-1874 DOI 10.1093/molbev/msw054.

Labonté JM, Suttle CA. 2013. Previously unknown and highly divergent ssDNA viruses populate the oceans. ISME Journal 7(11):2169-2177 DOI 10.1038/ismej.2013.110.

Lefeuvre P, Harkins GW, Lett JM, Briddon RW, Chase MW, Moury B, Martin DP. 2011. Evolutionary time-scale of the begomoviruses: evidence from integrated sequences in the Nicotiana genome. PLOS ONE 6(5):e19193 DOI 10.1371/journal.pone.0019193. 
Lefeuvre P, Lett JM, Varsani A, Martin DP. 2009. Widely conserved recombination patterns among single-stranded DNA viruses. Journal of Virology 83(6):2697-2707

DOI 10.1128/jvi.02152-08.

Lefort V, Longueville J-E, Gascuel O. 2017. SMS: smart model selection in PhyML. Molecular Biology and Evolution 34(9):2422-2424 DOI 10.1093/molbev/msx149.

Lefkowitz EJ, Dempsey DM, Hendrickson RC, Orton RJ, Siddell SG, Smith DB. 2018. Virus taxonomy: the database of the International Committee on Taxonomy of Viruses (ICTV). Nucleic Acids Research 46:D708-D717 DOI 10.1093/nar/gkx932.

Li CX, Shi M, Tian JH, Lin XD, Kang YJ, Chen LJ, Qin XC, Xu JG, Holmes EC, Zhang YZ. 2015. Unprecedented genomic diversity of RNA viruses in arthropods reveals the ancestry of negative-sense RNA viruses. Elife 4:e05378 DOI 10.7554/elife.05378.

Liu B, Preisser EL, Chu D, Pan H, Xie W, Wang S, Wu Q, Zhou X, Zhang Y. 2013. Multiple forms of vector manipulation by a plant-infecting virus: Bemisia tabaci and Tomato yellow leaf curl virus. Journal of Virology 87(9):4929-4937 DOI 10.1128/JVI.03571-12.

Liu HQ, Fu YP, Li B, Yu X, Xie JT, Cheng JS, Ghabrial SA, Li GQ, Yi XH, Jiang DH. 2011. Widespread horizontal gene transfer from circular single-stranded DNA viruses to eukaryotic genomes. BMC Evolutionary Biology 11(1):276 DOI 10.1186/1471-2148-11-276.

Liu S, Xie J, Cheng J, Li B, Chen T, Fu Y, Li G, Wang M, Jin H, Wan H, Jiang D. 2016. Fungal DNA virus infects a mycophagous insect and utilizes it as a transmission vector. Proceedings of the National Academy of Sciences of the United States of America 113(45):12803-12808 DOI 10.1073/pnas.1608013113.

Lopez-Bueno A, Tamames J, Velazquez D, Moya A, Quesada A, Alcami A. 2009. High diversity of the viral community from an Antarctic lake. Science 326(5954):858-861 DOI 10.1126/science.1179287.

Mahmoudabadi G, Phillips R. 2018. A comprehensive and quantitative exploration of thousands of viral genomes. Elife 7:e31955 DOI 10.7554/elife.31955.

Male MF, Kraberger S, Stainton D, Kami V, Varsani A. 2016. Cycloviruses, gemycircularviruses and other novel replication-associated protein encoding circular viruses in Pacific flying fox (Pteropus tonganus) faeces. Infection, Genetics, and Evolution 39:279-292 DOI 10.1016/j.meegid.2016.02.009.

Martin DP, Biagini P, Lefeuvre P, Golden M, Roumagnac P, Varsani A. 2011. Recombination in eukaryotic single stranded DNA viruses. Viruses 3(9):1699-1738 DOI 10.3390/V3091699.

McDaniel LD, Rosario K, Breitbart M, Paul JH. 2014. Comparative metagenomics: natural populations of induced prophages demonstrate highly unique, lower diversity viral sequences. Environmental Microbiology 16(2):570-585 DOI 10.1111/1462-2920.12184.

Mueller UG, Gerardo N. 2002. Fungus-farming insects: multiple origins and diverse evolutionary histories. Proceedings of the National Academy of Sciences of the United States of America 99(24):15247-15249 DOI 10.1073/pnas.242594799.

Muhire BM, Varsani A, Martin DP. 2014. SDT: a virus classification tool based on pairwise sequence alignment and identity calculation. PLOS ONE 9(9):e108277 DOI 10.1371/journal.pone.0108277.

Nádia CN, Raquel G, Francisco Á, Claude KY, Ward D, Mark Z, Lies L, Elisabeth H, Sara R, Francisco PF, Nuno S, Marc VR, João RM, Jelle M. 2017. Viral gut metagenomics of sympatric wild and domestic canids, and monitoring of viruses: insights from an endangered wolf population. Ecology and Evolution 7(12):4135-4146 DOI 10.1002/ece3.2991.

NCBI. 2018. RefSeq: NCBI Reference Sequence Database. Available at https://www.ncbi.nlm. nih.gov/refseq/2018. 
Ng TFF, Duffy S, Polston JE, Bixby E, Vallad GE, Breitbart M. 2011. Exploring the diversity of plant DNA viruses and their satellites using vector-enabled metagenomics on whiteflies. PLOS ONE 6(4):e19050 DOI 10.1371/journal.pone.0019050.

Ng TFF, Zhang W, Sachsenröder J, Kondov NO, Da Costa AC, Vega E, Holtz LR, Wu G, Wang D, Stine CO, Antonio M, Mulvaney US, Muench MO, Deng X, Ambert-Balay K, Pothier P, Vinjé J, Delwart E. 2015. A diverse group of small circular ssDNA viral genomes in human and non-human primate stools. Virus Evolution 1(1):vev017 DOI 10.1093/ve/vev017.

Oates SC, Miller MA, Hardin D, Conrad PA, Melli A, Jessup DA, Dominik C, Roug A, Tinker MT, Miller WA. 2012. Prevalence, environmental loading, and molecular characterization of Cryptosporidium and Giardia isolates from domestic and wild animals along the Central California Coast. Applied and Environmental Microbiology 78(24):8762-8772 DOI 10.1128/aem.02422-12.

Padilla-Rodriguez M, Rosario K, Breitbart M. 2013. Novel cyclovirus discovered in the Florida woods cockroach Eurycotis floridana (Walker). Archives of Virology 158(6):1389-1392 DOI 10.1007/s00705-013-1606-x.

Palmer TM, Young TP, Stanton ML, Wenk E. 2000. Short-term dynamics of an acacia ant community in Laikipia, Kenya. Oecologia 123(3):425-435 DOI 10.1007/s004420051030.

Pham HT, Bergoin M, Tijssen P. 2013a. Acheta domesticus volvovirus, a novel single-stranded circular DNA virus of the house cricket. Genome Announcements 1(2):e00079 DOI 10.1128/genomeA.00079-13.

Pham HT, Iwao H, Bergoin M, Tijssen P. 2013b. New volvovirus isolates from Acheta domesticus (Japan) and Gryllus assimilis (United States). Genome Announcements 1(3):e00328-13 DOI 10.1128/genomeA.00328-13.

Phan TG, Kapusinszky B, Wang CL, Rose RK, Lipton HL, Delwart EL. 2011. The fecal viral flora of wild rodents. PLOS Pathogens 7(9):e1002218 DOI 10.1371/journal.ppat.1002218.

Price MN, Dehal PS, Arkin AP. 2010. FastTree 2-approximately maximum-likelihood trees for large alignments. PLOS ONE 5(3):e9490 DOI 10.1371/journal.pone.0009490.

Quaiser A, Krupovic M, Dufresne A, Francez AJ, Roux S. 2016. Diversity and comparative genomics of chimeric viruses in Sphagnum-dominated peatlands. Virus Evolution 2(2):vew025 DOI 10.1093/ve/vew025.

Reavy B, Swanson MM, Cock PJA, Dawson L, Freitag TE, Singh BK, Torrance L, Mushegian AR, Taliansky M. 2015. Distinct circular single-stranded DNA viruses exist in different soil types. Applied and Environmental Microbiology 81(12):3934-3945 DOI 10.1128/aem.03878-14.

Rebrikov DV, Bogdanova EA, Bulina ME, Lukyanov SA. 2002. A new planarian extrachromosomal virus-like element revealed by subtractive hybridization. Molecular Biology 36(6):813-820 DOI 10.1023/a:1021629825320.

Rosario K, Breitbart M, Harrach B, Segalés J, Delwart E, Biagini P, Varsani A. 2017. Revisiting the taxonomy of the family Circoviridae: establishment of the genus Cyclovirus and removal of the genus Gyrovirus. Archives of Virology 162(5):1447-1463 DOI 10.1007/s00705-017-3247-y.

Rosario K, Dayaram A, Marinov M, Ware J, Kraberger S, Stainton D, Breitbart M, Varsani A. 2012. Diverse circular ssDNA viruses discovered in dragonflies (Odonata: Epiprocta). Journal of General Virology 93(Pt_12):2668-2681 DOI 10.1099/vir.0.045948-0.

Rosario K, Duffy S, Breitbart M. 2009. Diverse circovirus-like genome architectures revealed by environmental metagenomics. Journal of General Virology 90(10):2418-2424

DOI 10.1099/vir.0.012955-0. 
Rosario K, Duffy S, Breitbart M. 2012. A field guide to eukaryotic circular single-stranded DNA viruses: insights gained from metagenomics. Archives of Virology 157(10):1851-1871 DOI 10.1007/s00705-012-1391-y.

Rosario K, Fierer N, Miller S, Luongo J, Breitbart M. 2018. Diversity of DNA and RNA viruses in indoor air as assessed via metagenomic sequencing. Environmental Science \& Technology 52(3):1014-1027 DOI 10.1021/acs.est.7b04203.

Rosario K, Marr C, Varsani A, Kraberger S, Stainton D, Moriones E, Polston JE, Breitbart M. 2016. Begomovirus-associated satellite DNA diversity captured through vector-enabled metagenomic (VEM) surveys using whiteflies (Aleyrodidae). Viruses 8(2):36 DOI $10.3390 / v 8020036$.

Rosario K, Schenck RO, Harbeitner RC, Lawler SN, Breitbart M. 2015a. Novel circular single-stranded DNA viruses identified in marine invertebrates reveal high sequence diversity and consistent predicted intrinsic disorder patterns within putative structural proteins. Frontiers in Microbiology 6:696 DOI 10.3389/fmicb.2015.00696.

Rosario K, Seah Y, Marr C, Varsani A, Kraberger S, Stainton D, Moriones E, Polston J, Duffy S, Breitbart M. 2015b. Vector-enabled metagenomic (VEM) surveys using whiteflies (Aleyrodidae) reveal novel begomovirus species in the New and Old Worlds. Viruses 7(10):5553-5570 DOI 10.3390/v7102895.

Roux S, Enault F, Bronner G, Vaulot D, Forterre P, Krupovic M. 2013. Chimeric viruses blur the borders between the major groups of eukaryotic single-stranded DNA viruses. Nature Communications 4(1):2700 DOI 10.1038/ncomms3700.

Shi M, Lin X-D, Chen X, Tian J-H, Chen L-J, Li K, Wang W, Eden J-S, Shen J-J, Liu L, Holmes EC, Zhang Y-Z. 2018a. The evolutionary history of vertebrate RNA viruses. Nature 556(7700):197-202 DOI 10.1038/s41586-018-0012-7.

Shi M, Lin XD, Tian JH, Chen LJ, Chen X, Li CX, Qin XC, Li J, Cao JP, Eden JS, Buchmann J, Wang W, Xu J, Holmes EC, Zhang YZ. 2016a. Redefining the invertebrate RNA virosphere. Nature 540(7634):539-543 DOI 10.1038/nature20167.

Shi M, Lin XD, Vasilakis N, Tian JH, Li CX, Chen LJ, Eastwood G, Diao XN, Chen MH, Chen X, Qin XC, Widen SG, Wood TG, Tesh RB, Xu JG, Holmes EC, Zhang YZ. 2016b. Divergent viruses discovered in arthropods and vertebrates revise the evolutionary history of the Flaviviridae and related viruses. Journal of Virology 90(2):659-669 DOI 10.1128/Jvi.02036-15.

Shi M, Zhang YZ, Holmes EC. 2018b. Meta-transcriptomics and the evolutionary biology of RNA viruses. Virus Research 243:83-90 DOI 10.1016/j.virusres.2017.10.016.

Sicard A, Zeddam JL, Yvon M, Michalakis Y, Gutierrez S, Blanc S. 2015. Circulative nonpropagative aphid transmission of nanoviruses: an oversimplified view. Journal of Virology 89(19):9719-9726 DOI 10.1128/JVI.00780-15.

Sickmeier M, Hamilton JA, LeGall T, Vacic V, Cortese MS, Tantos A, Szabo B, Tompa P, Chen J, Uversky VN, Obradovic Z, Dunker AK. 2007. DisProt: the database of disordered proteins. Nucleic Acids Research 35(Database):D786-D793 DOI 10.1093/nar/gkl893.

Söding J, Biegert A, Lupas AN. 2005. The HHpred interactive server for protein homology detection and structure prediction. Nucleic Acids Research 33(Web Server):W244-W248 DOI 10.1093/nar/gki408.

Steel O, Kraberger S, Sikorski A, Young LM, Catchpole RJ, Stevens AJ, Ladley JJ, Coray DS, Stainton D, Dayaram A, Julian L, Van Bysterveldt K, Varsani A. 2016. Circular replication-associated protein encoding DNA viruses identified in the faecal matter of 
various animals in New Zealand. Infection, Genetics and Evolution 43:151-164

DOI 10.1016/j.meegid.2016.05.008.

Stork NE. 2018. How many species of insects and other terrestrial arthropods are there on Earth? Annual Review of Entomology 63(1):31-45 DOI 10.1146/annurev-ento-020117-043348.

Stöver BC, Müller KF. 2010. TreeGraph 2: combining and visualizing evidence from different phylogenetic analyses. BMC Bioinformatics 11(1):7 DOI 10.1186/1471-2105-11-7.

Tikhe CV, Husseneder C. 2017. Metavirome sequencing of the termite gut reveals the presence of an unexplored bacteriophage community. Frontiers in Microbiology 8:2548

DOI 10.3389/fmicb.2017.02548.

Tokarz R, Sameroff S, Tagliafierro T, Jain K, Williams SH, Cucura DM, Rochlin I, Monzon J, Carpi G, Tufts D, Diuk-Wasser M, Brinkerhoff J, Lipkin WI. 2018. Identification of novel viruses in Amblyomma americanum, Dermacentor variabilis, and Ixodes scapularis ticks. mSphere 3(2):e00614-17 DOI 10.1128/mSphere.00614-17.

Tsai IJ, Zarowiecki M, Holroyd N, Garciarrubio A, Sanchez-Flores A, Brooks KL, Tracey A, Bobes RJ, Fragoso G, Sciutto E, Aslett M, Beasley H, Bennett HM, Cai J, Camicia F, Clark R, Cucher M, De Silva N, Day TA, Deplazes P, Estrada K, Fernández C, Holland PWH, Hou J, Hu S, Huckvale T, Hung SS, Kamenetzky L, Keane JA, Kiss F, Koziol U, Lambert O, Liu K, Luo X, Luo Y, Macchiaroli N, Nichol S, Paps J, Parkinson J, Pouchkina-Stantcheva N, Riddiford N, Rosenzvit M, Salinas G, Wasmuth JD, Zamanian M, Zheng Y, The Taenia solium Genome C, Cai X, Soberón X, Olson PD, Laclette JP, Brehm K, Berriman M. 2013. The genomes of four tapeworm species reveal adaptations to parasitism. Nature 496(7443):57-63 DOI 10.1038/nature12031.

Varsani A, Krupovic M. 2017. Sequence-based taxonomic framework for the classification of uncultured single-stranded DNA viruses of the family Genomoviridae. Virus Evolution 3(1):vew037 DOI 10.1093/ve/vew037.

Varsani A, Krupovic M. 2018. Smacoviridae: a new family of animal-associated single-stranded DNA viruses. Archives of Virology 163(7):2005-2015 DOI 10.1007/s00705-018-3820-z.

Varsani A, Martin DP, Navas-Castillo J, Moriones E, Hernandez-Zepeda C, Idris A, Zerbini FM, Brown JK. 2014a. Revisiting the classification of curtoviruses based on genome-wide pairwise identity. Archives of Virology 159(7):1873-1882 DOI 10.1007/s00705-014-1982-x.

Varsani A, Navas-Castillo J, Moriones E, Hernandez-Zepeda C, Idris A, Brown JK, Murilo Zerbini F, Martin DP. 2014b. Establishment of three new genera in the family Geminiviridae: Becurtovirus, Eragrovirus and Turncurtovirus. Archives of Virology 159(8):2193-2203 DOI 10.1007/s00705-014-2050-2.

Varsani A, Roumagnac P, Fuchs M, Navas-Castillo J, Moriones E, Idris A, Briddon RW, Rivera-Bustamante R, Murilo Zerbini F, Martin DP. 2017. Capulavirus and Grablovirus: two new genera in the family Geminiviridae. Archives of Virology 162:1819-1831

DOI 10.1007/s00705-017-3268-6.

Waits K, Edwards MJ, Cobb IN, Fontenele RS, Varsani A. 2018. Identification of an anellovirus and genomoviruses in ixodid ticks. Virus Genes 54(1):155-159 DOI $10.1007 /$ s11262-017-1520-5.

Wang B, Sun L-D, Liu H-H, Wang Z-D, Zhao Y-K, Wang W, Liu Q. 2018. Molecular detection of novel circoviruses in ticks in northeastern China. Ticks and Tick-Borne Diseases 9(4):836-839 DOI 10.1016/j.ttbdis.2018.03.017.

Watanabe S, Bressan A. 2013. Tropism, compartmentalization and retention of banana bunchy top virus (Nanoviridae) in the aphid vector Pentalonia nigronervosa. Journal of General Virology 94(Pt_1):209-219 DOI 10.1099/vir.0.047308-0. 
Whon TW, Kim MS, Roh SW, Shin NR, Lee HW, Bae JW. 2012. Metagenomic characterization of airborne viral DNA diversity in the near-surface atmosphere. Journal of Virology 86(15):8221-8231 DOI 10.1128/Jvi.00293-12.

Yoon HS, Price DC, Stepanauskas R, Rajah VD, Sieracki ME, Wilson WH, Yang EC, Duffy S, Bhattacharya D. 2011. Single-cell genomics reveals organismal interactions in uncultivated marine protists. Science 332(6030):714-717 DOI 10.1126/science.1203163.

Young TP, Stubblefield CH, Isbell LA. 1997. Ants on swollen-thorn acacias: species coexistence in a simple system. Oecologia 109(1):98-107 DOI 10.1007/s004420050063.

Yu X, Li B, Fu Y, Jiang D, Ghabrial SA, Li G, Peng Y, Xie J, Cheng J, Huang J, Yi X. 2010. A geminivirus-related DNA mycovirus that confers hypovirulence to a plant pathogenic fungus. Proceedings of the National Academy of Sciences of the United States of America 107(18):8387-8392 DOI 10.1073/pnas.0913535107.

Yusseff-Vanegas SZ, Agnarsson I. 2017. DNA-barcoding of forensically important blow flies (Diptera: Calliphoridae) in the Caribbean Region. PeerJ 5:e3516 DOI 10.7717/peerj.3516.

Zhang W, Li L, Deng X, Kapusinszky B, Pesavento PA, Delwart E. 2014. Faecal virome of cats in an animal shelter. Journal of General Virology 95(Pt_11):2553-2564 DOI 10.1099/vir.0.069674-0.

Zuker M. 2003. Mfold web server for nucleic acid folding and hybridization prediction. Nucleic Acids Research 31(13):3406-3415 DOI 10.1093/nar/gkg595. 